Research Article

\title{
Seismic Fragility Analysis of Bridge Group Pile Foundations considering Fluid-Pile-Soil Interaction
}

\author{
Chao Zhang, ${ }^{1}$ Chengwang $\mathrm{Wu}^{1}$ and Piguang Wang ${ }^{2}{ }^{2}$ \\ ${ }^{1}$ College of Civil Engineering, Fuzhou University, Fuzhou 35002, China \\ ${ }^{2}$ College of Architecture and Civil Engineering, Beijing University of Technology, Beijing 100124, China
}

Correspondence should be addressed to Piguang Wang; wangpiguang1985@126.com

Received 19 March 2020; Revised 21 June 2020; Accepted 11 July 2020; Published 3 August 2020

Academic Editor: Mahmoud Bayat

Copyright (c) 2020 Chao Zhang et al. This is an open access article distributed under the Creative Commons Attribution License, which permits unrestricted use, distribution, and reproduction in any medium, provided the original work is properly cited.

The cross-sea bridges play an important role to promote the development of regional economy. These bridges located in earthquake-prone areas may be subjected to severe earthquakes during their lifetime. Group pile foundations have been widely used in cross-sea bridges due to their structural efficiency, ease of construction, and low cost. This paper investigates the seismic performance of bridge pile foundation based on the seismic fragility analysis. Based on the analysis platform OpenSees, the threedimensional finite model of the bridge pile foundation is developed, where the pile-water interaction is replaced by the added mass method, nonlinear $p-y, t-z$, and $q-z$ elements are used to simulate pile-soil interaction, and the displacement of the surface ground motion due to seismic excitations is applied on all spring supports. The seismic fragility curves of the bridge pile foundation are generated by using the earthquake records recommended by FEMA P695 as input motions. The curvature ductility based fragility curves are obtained using seismic responses for different peak ground accelerations. The effects of pile-water interaction, soil conditions, and different types of ground motions on the bridge pier fragilities are studied and discussed. Seismic fragility of the pier-group pile system shows that Sec C (the bottom section of the pier) is the most vulnerable section in the example fluidstructure-soil interaction (FSSI) system for all four damage LSs. The seismic responses of Sec E (a pile section located at the interface of the soil layer and water layer) are much lower than other sections. The parameter analysis shows that pile-water interaction has slight influence (less than 5\%) on the fragility curves of the bridge pier. For the bridge group pile foundations considering the fluid-pile-soil interaction, PNF may induce larger seismic response than far-field (FF) and no-pulse near field (NNF). The bridge pile foundation in stiff soil is most vulnerable to seismic damage than soft condition.

\section{Introduction}

With the development of economy and advancement of technology, more and more cross-sea bridges have been constructed around the world in recent decades. The crosssea bridges located in earthquake-prone areas, such as the eastern coast of China or the western coast of the USA, may be subjected to earthquake action. The strong ground motion can destruct the cross-sea bridges, which will cause great economic loss and confusion of society. Therefore, seismic design of cross-sea bridges has become an urgent research topic. In recent years, pile group foundation has been widely used in cross-sea bridges or brides in deep water due to the structural efficiency, ease of construction, and low cost [1], where most of these foundations have their piles partially or totally submerged in deep water. It should be noted that the dynamic behavior of structures in deep water requires special considerations due to the interaction of water with structure [2-4]. The earthquake-induced hydrodynamic force on the structure may increase the structural responses. The experiment conducted by Wei et al. [5] also indicated that fluid-structure interaction had significant effects on the dynamic response of bridge pile foundations submerged in water. In addition to the fluid-structure interaction (FSI), the soil-structure interaction (SSI) can play an important role in the seismic responses of bridges [6-10]. Consequently, it is important to evaluate the seismic responses of cross-sea bridges considering SSI. This study mainly focuses on the 
seismic responses of bridge pile group foundation considering fluid-structure-soil interaction (FSSI).

The earthquake-induced hydrodynamic forces on a single cylinder [11-13] and the seismic responses of cylinder surrounded by water [14-16] have been investigated widely in recent decades. The results indicated that effect of free surface waves on the earthquake-induced hydrodynamic force can be neglected and effect of water compressibility is quite important when the dimensionless frequency is greater than unity. Wang et al. [17] developed an accurate time-domain model to replace the compressible water in the water-cylinder interaction analysis. It should be noted that the incompressible water can be replaced by an added mass [3]. Recently, a series of simplified formulas to evaluate the added mass of a single cylinder are presented by assuming the cylinder rigid, such as the circular cylinder $[18,19]$, the elliptical cylinder $[20,21]$, the round-ended and rectangular cylinders [22], and the circular tapered cylinders [23]. In addition, the simple added mass models for a flexible cylinder vibrating in water were also proposed by Han and Xu [24], Yang and Li [25], and Wang et al. [26]. A few studies were carried out to investigate the hydrodynamic interaction of multiple cylinders subjected to earthquake loading [27, 28]. The results indicated that the effects of interaction of multiple cylinders with water on the seismic responses of the cylinder increase as the relative distance decreases. Wang et al. [29] developed an accurate finite element model to evaluate the earthquake-induced hydrodynamic forces on multiple cylinders. The method presented by Wang et al. [29] is used to calculate the coefficients of the pile group in the present study.

It is well known that the SSI can have significant influence on the seismic responses of structures. Generally, two methods including the integrated finite element model [30-32] and the substructure model [33-35] are always adopted to model the SSI on the dynamic responses of offshore structures subjected to earthquake action. The integrated finite element model is inconvenient to use the model in structural seismic design because of its long time costs in modeling and calculation. The substructure models are more applicable to be used in structural seismic design than the above model. In the substructure model, the pile-soil interaction can be replaced by linear springs [35] or nonlinear springs based on $p-y$ curves [36], where all of the soil springs are attached to the pile. There are mainly two different methods for applying ground motion when the pile-soil interaction replaced by soil springs. One method is uniform seismic excitations [37], where the surface ground motion is applied to all soil spring boundaries from the bedrock and to the seabed. The other method is nonuniform seismic excitations [38], where different motion obtained by one-dimensional free-field analysis is applied at each support of soil springs. The research conducted by [39] indicated that the offshore structures will be safe by using the uniform seismic excitations. Therefore, the nonlinear springs based on $p-y$ curves and the uniform seismic excitations are adopted in the present study.
However, a few studies have been carried out to analyze the seismic response of cross-sea bridges considering FSSI. The main objective of this study is to obtain fragility curves for a typical bridge pile group foundation considering FSSI. Fragility curves are an appropriate tool to evaluate the seismic vulnerability of structures and to estimate the probability of exceeding a certain damage level for a specific seismic ground shaking intensity [40]. In this paper, fragility curves for the bridge pile group foundation are estimated by an analytical approach, specifically by conducting an incremental dynamic analysis. The effects of water, soil, and different kinds of ground motions on the seismic behavior of the bridge pile group foundation are quantitatively analyzed.

1.1. Numerical Modeling. Based on a sea-crossing bridge in the southeast coastal areas of China, a bridge pier on highcap pile group foundations is selected as an example. The bridge pier comprises a concrete hollow pier, a pile cap, and 15 piles. Figure 1 shows the elevation view and component cross sections of the bridge pier. A three-dimensional finite element model of the pier-pile system considering FSSI is developed using the open-source software platform OpenSees [41], as shown in Figure 2. The detailed description of the pier, pile, pile-soil interaction, and pile-water interaction is provided herein.

1.2. Bridge and Pile. The heights of the pier, pile cap, and bridge pile foundation are $38 \mathrm{~m}, 5 \mathrm{~m}$, and $80 \mathrm{~m}$, respectively. The upper $40 \mathrm{~m}$ of pile group is submerged in seawater, and the lower $40 \mathrm{~m}$ is embedded in subsea soils. Figure 1 shows the cross sections ranged from A-A to E-E and locations of reinforcing bars of the pier and the pile foundations. Poisson's ratio of steel and concrete is 0.3 and 0.2 , respectively. The rebar's diameter of the pier and the piles are $28 \mathrm{~mm}$ and $36 \mathrm{~mm}$, respectively.

Figure 3 shows the material behavior of steel of HRB335 and HRB400 and the concrete of C40 and C30. The C40 concrete is used for the pier column and pile cap, while C30 concrete is used for pile group foundations The standard compressive strengths of the concrete are 26.8 and $20.1 \mathrm{MPa}$ for the pier column and the piles, respectively. The yield strengths of longitudinal bars used for the pier column and pile foundations are $335 \mathrm{MPa}$ and $400 \mathrm{MPa}$, respectively, while the yield strengths of stirrups are $335 \mathrm{MPa}$. The torsional and moments of inertial in the two in-plane directions are $57283.3 \mathrm{~m} 4,10953.6 \mathrm{~m}^{4}$, and $46329.7 \mathrm{~m}^{4}$ for the pile cap, respectively. The section area and elastic modulus of concrete for the pile cap are $519.9 \mathrm{~m}^{2}$ and $32.5 \mathrm{GPa}$, respectively. The moments of inertia of the pile cap cross section about the $x$-axis is $10953.6 \mathrm{~m}^{4}$, while about the $y$-axis is $46329.7 \mathrm{~m}^{4}$.

The bridge pier is modeled with the displacement-based beam-column element, which is based on the displacement formulation, and considers the spread of plasticity along the element. Based on the fiber model in the OpenSees program, the hysteretic behavior of bridge column specimens is investigated by Han et al. [42]. The results indicated that the fiber model agrees well with the experimental results. In the present study, Concrete 01 from the material library in 


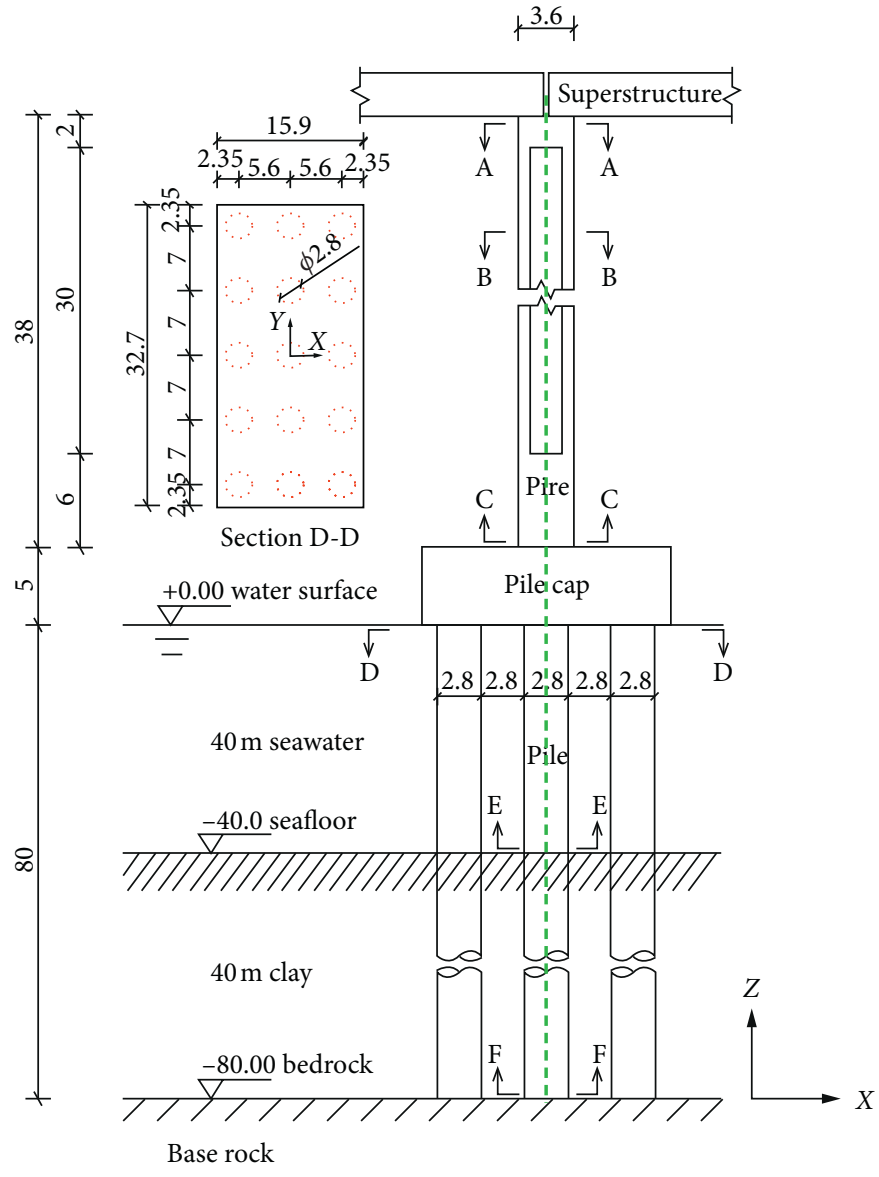

(a)

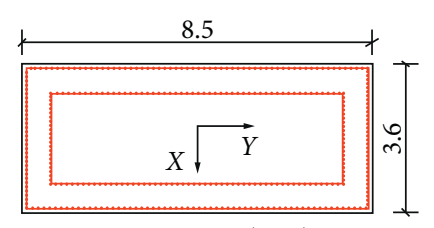

Section A-A (C-C)

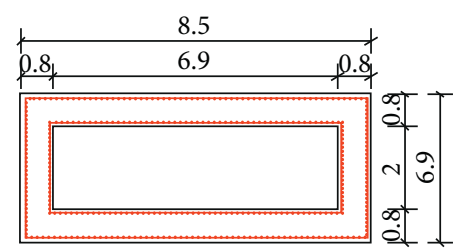

Section B-B

Longitudinal rebar: $332 \Phi 28$

Stirrups: $\$ 16 @ 80 \mathrm{~mm}$

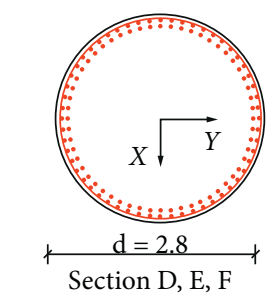

Longitudinal rebar: $112 \$ 36$

Stirrups: $\$ 12 @ 100 \mathrm{~mm}$

(b)

Figure 1: Schematic view of the bridge pile foundation and key sections. (a) Elevation view (unit: $\mathrm{m}$ ) and (b) cross sections (unit: $\mathrm{m}$ ).

OpenSees proposed by Scott et al. [43] and Reinforcing Steel from the material library in OpenSees proposed by Chang and Mander [44] are selected to simulate the concrete behavior and the reinforcement behavior. Figure 2 shows the finite element model for the connections between the piles and surrounding soil layers. For each pile, the bottom $40 \mathrm{~m}$ embedded in the subsea soil layers consists of 20 pile elements and 21 pile nodes and the upper $40 \mathrm{~m}$ submerged in seawater consists of 20 pile elements and 20 pile nodes.

1.3. Pile-Soil Interaction. The soil is assumed to be soft clay. The nonlinear $p-y, t-z$ and $q-z$ elements developed by Boulanger et al. $[45,46]$ are used to describe the interaction of pile with soil. Figure 4 shows the characteristics of the nonlinear $p-y$ spring components, which is conceptualized as consisting of elastic, plastic, and gap components in series. The gap component consists of a nonlinear closure spring in parallel with a nonlinear drag spring. In addition, a dashpot in parallel with the elastic component is used to model the radiation damping.

The constitutive behavior of the abovementioned springs can be defined by uniaxial materials PySimple1, TzSimple1, and QzSimple1 in OpenSees, where parameters $p_{\text {ult }}, y_{50}$, and $C_{d}$ are required for PySimple $1, t_{\mathrm{ult}}$ and $z_{50}$ for TzSimple1, and $q_{\text {ult }}$ and $z_{50}$ for QzSimple1. Distributed nonlinear zerolength elements with $p-y, t-z$ and $q-z$ materials are created at the pile nodes. The properties of each $p-y, t-z$, and $q-z$ element are derived based on the properties of each layer at the corresponding depth. It should be noted that $p_{\text {ult }}$ and $y_{50}$ proposed by [47] and $t_{\mathrm{ult}}, q_{\mathrm{ult}}$, and $z_{50}$ based on the API [48] recommendations are adopted in the present study. This study uses $C_{\mathrm{u}}=40 \mathrm{kPa}, \varepsilon_{50}=0.01, J=0.375$, and $\gamma=10 \mathrm{kN} /$ $\mathrm{m}^{3}$, where $C_{\mathrm{u}}, \varepsilon_{50}, J$, and $\gamma$ denote the undrained shear strength, the strain corresponding to one-half the maximum stress on laboratory undrained compression tests of undisturbed soil, an empirical dimensionless constant, and the submerged unit weight.

The spring nodes and the fixed nodes with three translational degrees of freedom are created, which are initially fixed in all degrees of freedom. The spring nodes of the zero-length elements share equal degrees of freedom in all translational directions with the pile nodes. The nodes on the other end are subjected to the ground motion of the seismic loading. The uniform seismic excitations are adopted in the present study. Therefore, the displacement 


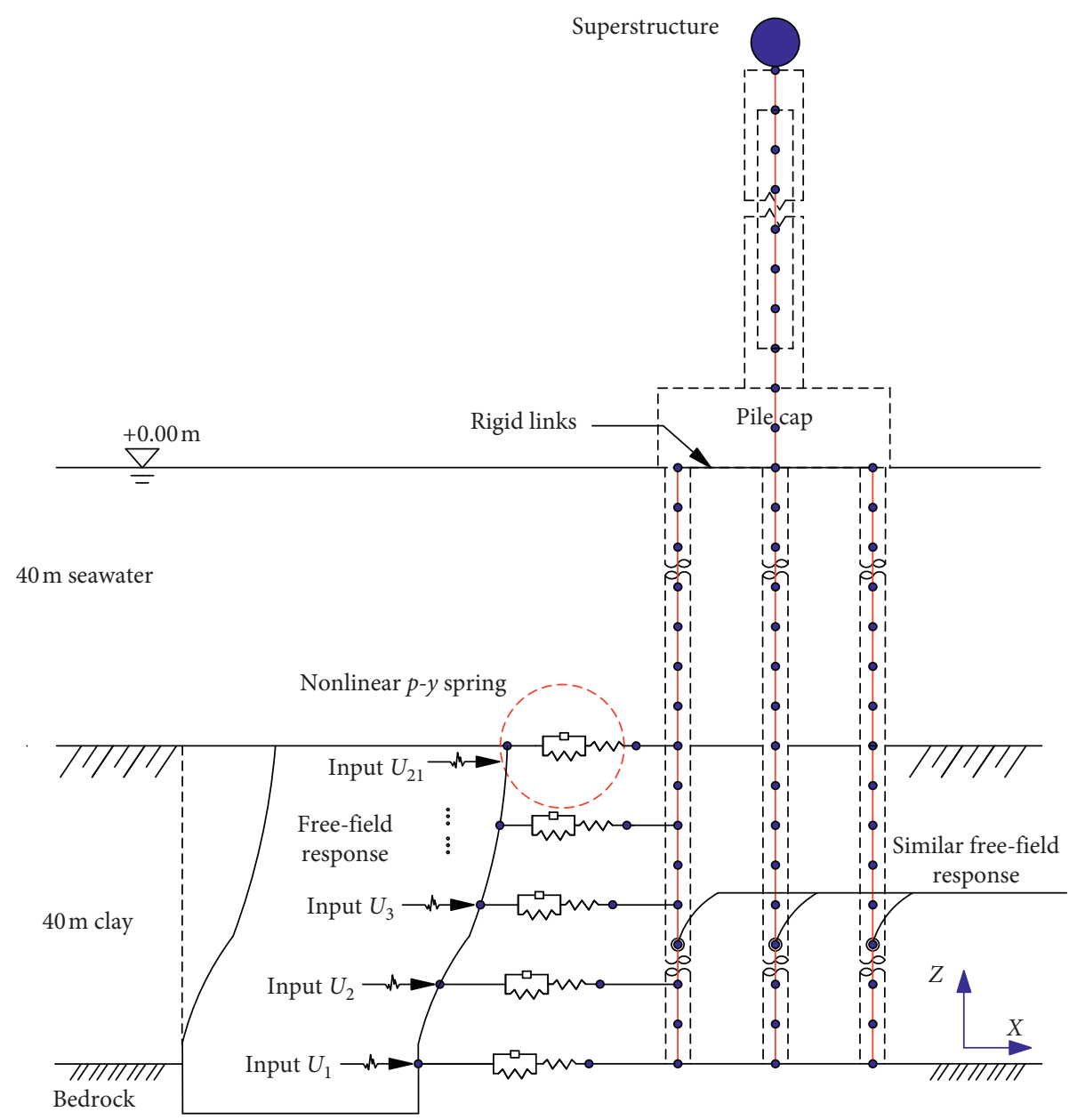

Figure 2: Soil-structure interaction model (unit: m).

of the surface ground motion is applied on all spring supports.

1.4. Pile-Water Interaction. The fluid damping effects on structural response include the viscous damping due to the fluid viscosity and the radiation damping due to the water compressible and free surface waves. Neglecting the fluid viscosity, many studies were performed to study the earthquake-induced hydrodynamic pressures on cylinders $[3,11,15,17,21,24,26,29]$. The study conducted by Liaw and Chopra [3] indicated that water compressibility and free surface waves can be neglected in solving the earthquakeinduced hydrodynamic pressure on circular cylinders. Then, the pile-water interaction can be conveniently modeled as the product of an added mass of water and the acceleration of the pile. In this study, the added mass is used to represent the lateral resistance of the pile-water interaction. The simplified formula of the added mass for a single pile can be expressed as [21]

$$
\begin{aligned}
m(\bar{z}) & =\rho_{w} \pi r_{0}^{2} \alpha\left[1-\bar{z} e^{\beta(\bar{z}-1)}\right], \\
\alpha & =0.918 e^{-0.468 l}+0.155 e^{0.015 l}, \\
\beta & =1.248 l^{-1.194}+2.156,
\end{aligned}
$$

where $\bar{z}=(z / h), l=\left(2 r_{0} / h\right), h$ is the water depth, $r_{0}$ is the radius of the pile, $\rho_{w}$ is the water density, and $z$ is the distance above seabed.

Recently, Wang et al. [29] proposed an accurate and efficient finite element model to calculate the earthquakeinduced hydrodynamic forces on multiple circular cylinders. This numerical model is used to calculate the coefficients of the pile group for the added mass in the present study. The coefficients of the pile group for these 15 piles with different water depth are illustrated in Table 1.

1.5. FEM and Validation. Based on the OpenSees platform, a $3 \mathrm{D}$ finite element analysis model of group pile bridge towers was established. The schematic diagram of FEM is shown in Figure 5(a). In the model, the soil-pile interaction is simulated by the nonlinear zero-length elements. The pile-water interaction is considered by added mass shown in Figure 5(a).

For the FEM model comparison, the FEM of bridge group pile foundations is established by SAP2000. The pier and piles are simulated by the linear frame element. Except for the sections of piers, the section definition of the SAP2000 model is completely equal to the OpenSees model. For the pier section, the displacement-based beam-column 


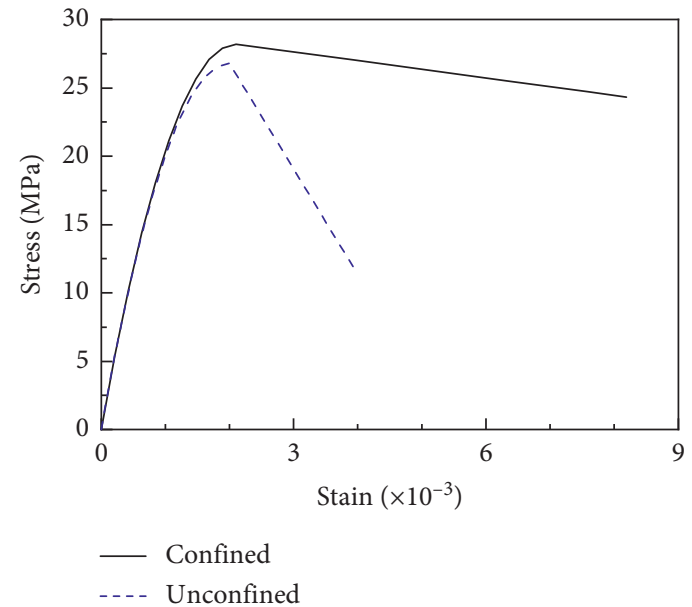

(a)

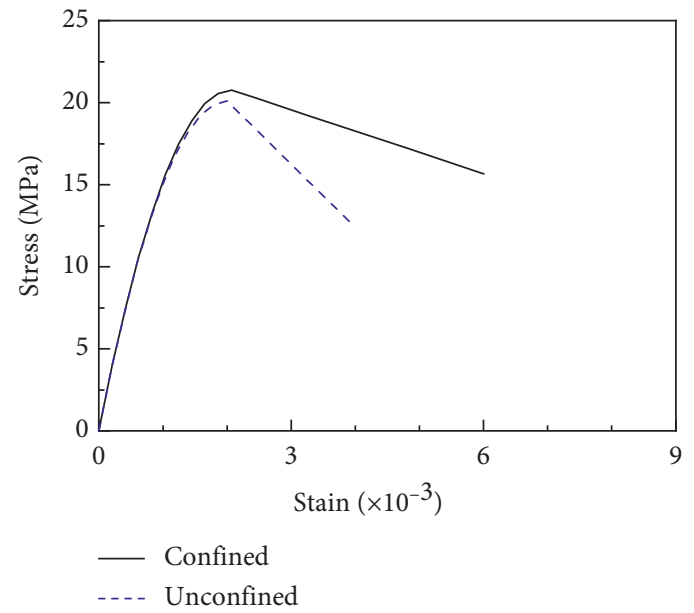

(c)

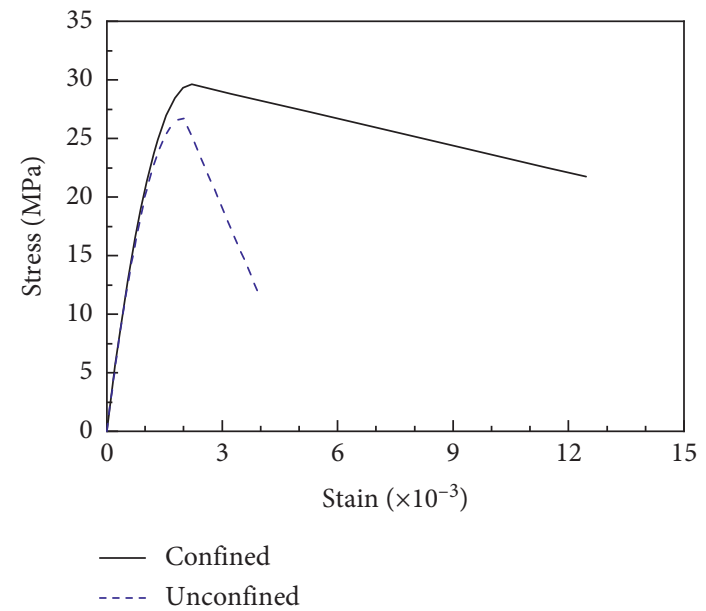

(b)

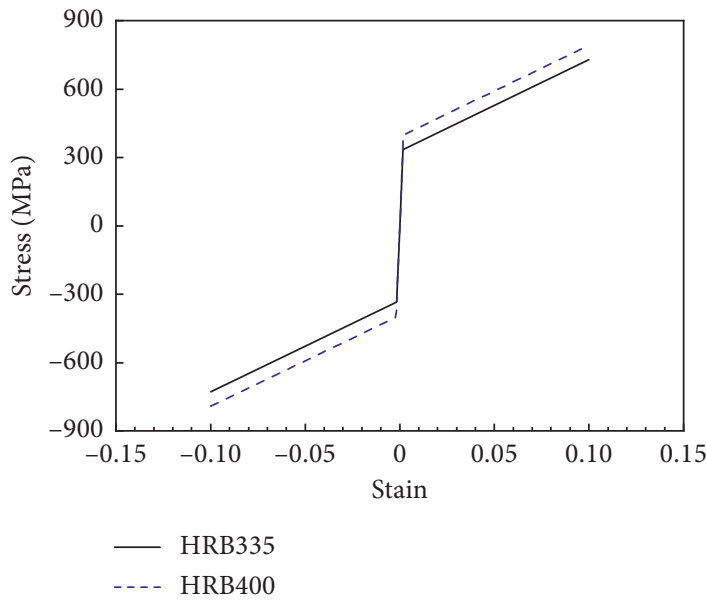

(d)

Figure 3: Material constitutive model. (a) Concrete for Sec A/C, (b) concrete for Sec B, (c) concrete for Sec D, and (d) steel.

TABLE 1: The coefficients of the pile group for 15 piles.

\begin{tabular}{lccccccc}
\hline \multirow{2}{*}{ Pile number } & \multicolumn{7}{c}{$h(\mathrm{~m})$} \\
& 10 & 15 & 20 & 25 & 30 & 35 & 40 \\
\hline 1 & 0.897 & 0.908 & 0.920 & 0.930 & 0.938 & 0.944 & 0.950 \\
2 & 0.923 & 0.944 & 0.962 & 0.976 & 0.987 & 0.996 & 1.003 \\
3 & 0.926 & 0.950 & 0.970 & 0.985 & 0.997 & 1.006 & 1.014 \\
4 & 0.923 & 0.944 & 0.962 & 0.976 & 0.987 & 0.996 & 1.003 \\
5 & 0.897 & 0.908 & 0.920 & 0.930 & 0.938 & 0.945 & 0.950 \\
6 & 0.807 & 0.825 & 0.842 & 0.855 & 0.865 & 0.873 & 0.880 \\
7 & 0.838 & 0.871 & 0.896 & 0.915 & 0.929 & 0.940 & 0.949 \\
8 & 0.842 & 0.879 & 0.908 & 0.928 & 0.943 & 0.955 & 0.965 \\
9 & 0.837 & 0.870 & 0.896 & 0.915 & 0.929 & 0.940 & 0.948 \\
10 & 0.807 & 0.826 & 0.843 & 0.856 & 0.866 & 0.874 & 0.880 \\
11 & 0.897 & 0.909 & 0.920 & 0.930 & 0.938 & 0.945 & 0.950 \\
12 & 0.923 & 0.944 & 0.962 & 0.976 & 0.987 & 0.996 & 1.003 \\
13 & 0.926 & 0.949 & 0.969 & 0.985 & 0.996 & 1.006 & 1.013 \\
14 & 0.923 & 0.944 & 0.962 & 0.976 & 0.987 & 0.996 & 1.003 \\
15 & 0.897 & 0.908 & 0.920 & 0.930 & 0.938 & 0.945 & 0.950 \\
\hline
\end{tabular}

element with fiber is used in the OpenSees model. In contrast, the pier in SAP2000 is simulated by linear frame elements. Therefore, the cross section parameters of pier

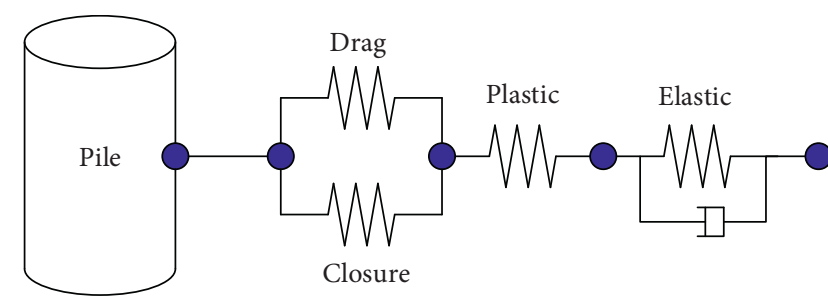

FIgURE 4: Components of dynamic $p-y$ element.

section in the SAP2000 model are equivalently converted according to the OpenSees model. The FEM based on SAP2000 is shown in Figure 5(b).

Both vibration periods of the first 3 modes and seismic responses on critical sections of the OpenSees model and SAP2000 model are compared in Table 2. It can be seen that both the vibration periods and seismic responses agree well with each model. Therefore, the validated FEM model based on the OpenSees platform can be used in the following studies. 


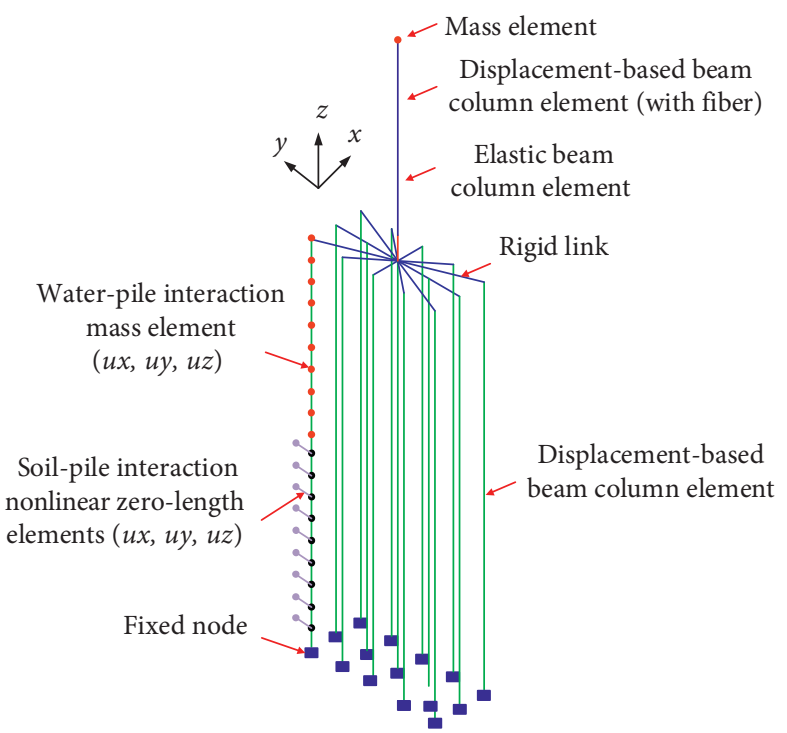

(a)

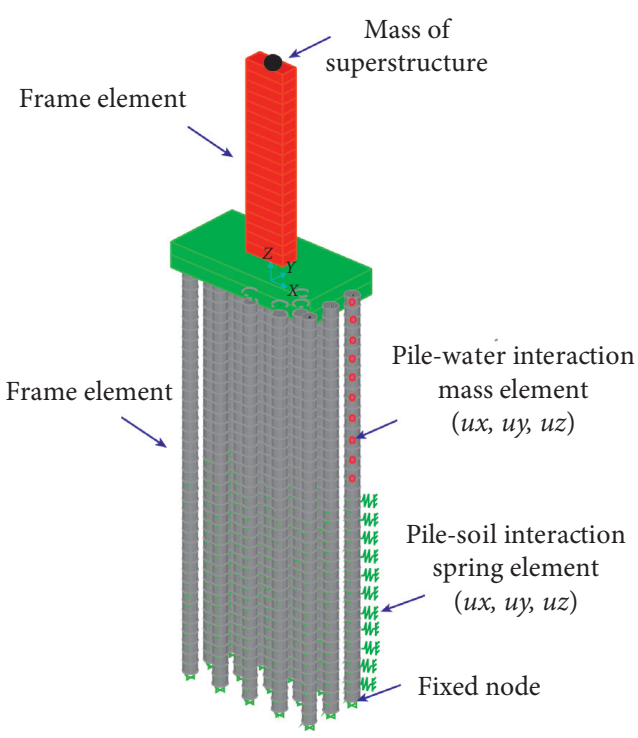

(b)

Figure 5: The 3D finite element model of bridge group pile foundations. (a) Model A (OpenSees) and (b) Model A (SAP 2000).

\section{Seismic Fragility Analysis of the System}

2.1. Methodology of Component Fragility Approach. The seismic fragility function, which defines the probability of physical damage as a function of ground motion intensity, is widely used to develop vulnerability information for bridges [49-52].

The seismic fragility curves are the relation between the ground motion intensity measure (IM) and the seismic demand $(D)$ of structures and modeled as lognormal distribution [53]:

$$
P[D \geq C \mid \mathrm{IM}]=1-\Phi\left[\frac{\ln \left(S_{C} / S_{D}\right)}{\beta_{D \mid \mathrm{IM}}}\right],
$$

where $C$ is structural capacity; $S_{C}$ is median estimate of the capacity; $S_{D}$ and $\beta_{D \mid \mathrm{IM}}$ are the median value and dispersion of the structural demand as a function of an IM, respectively; and $\Phi[\cdot]$ denotes the cumulative standard normal distribution function.

Generally, the relation between $S_{D}$ and IM can be characterized by a powerful log-linear model [53], defined as

$$
S_{D}=a \mathrm{IM}^{b} \text { or } \ln \left(S_{D}\right)=\ln (a)+b \ln (\mathrm{IM}) \text {, }
$$

where $a$ and $b$ are the power-law model coefficient parameters. And the dispersion of the demand $\beta_{D \mid \mathrm{IM}}$ can be estimated by

$$
\beta_{D \mid \mathrm{IM}} \cong \sqrt{\frac{\sum_{i=1}^{N}\left(\ln \left(D_{i}\right)-(\ln (a)+b \ln (\mathrm{IM}))\right)^{2}}{N-2}},
$$

where $D_{i}$ and $N$ are the $i$ th realization of structural seismic demand and the number of conducted nonlinear time history analyses (NHTA), respectively.

Substituting equation (5) into equation (4), the fragility function can be rewritten as
TABLE 2: FEM model validation of periods and seismic responses.

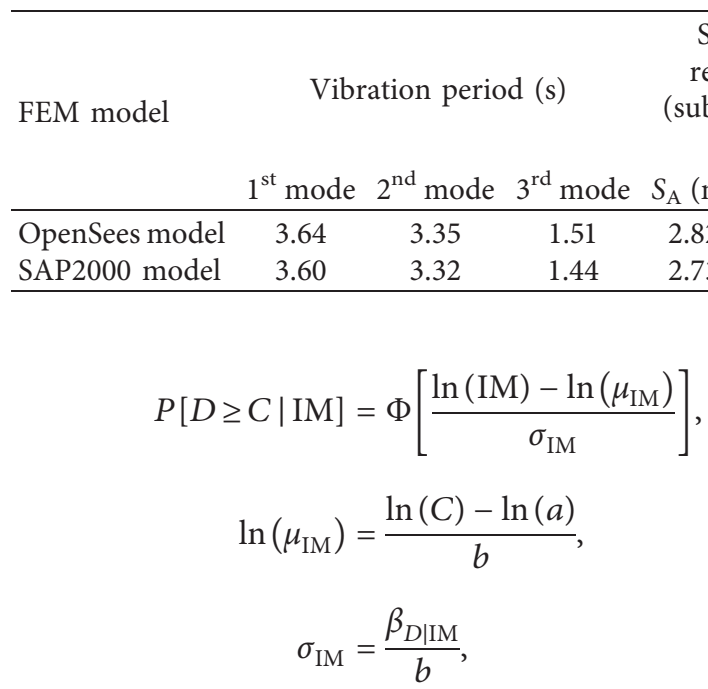

in which $\mu_{\mathrm{IM}}$ and $\sigma_{\mathrm{IM}}$ represent the median and dispersion of the generated fragility curve.

2.2. Incremental Dynamic Analysis. Incremental dynamic analysis (IDA) is a computer analysis technique that is widely performed to assess the seismic performance of structures subjected to earthquake loads. IDA is used to generate the analytical fragility curves in the present study. For carrying out the IDA, the PGA is utilized as the intensity measure (IM) of each record, and PGA of all ground motion records is scaled from $0.1 \mathrm{~g}$ to $1.5 \mathrm{~g}$ with the increment of $0.1 \mathrm{~g}$.

The longitudinal curvature ductility $(\mu)$ of the pier and pile sections is assumed as engineering demand parameters (EDPs). The curvature ductility limit states are also evaluated 
TABLE 3: The DI values corresponding to the four LSs of each component.

\begin{tabular}{|c|c|c|c|c|c|}
\hline $\begin{array}{l}\text { Bridge } \\
\text { component }\end{array}$ & Damage state & $\begin{array}{c}\text { Slight } \\
(\mathrm{DS}=1)\end{array}$ & $\begin{array}{c}\text { Moderate } \\
(\mathrm{DS}=2)\end{array}$ & $\begin{array}{c}\text { Extensive } \\
(\mathrm{DS}=3)\end{array}$ & $\begin{array}{l}\text { Collapse } \\
(\mathrm{DS}=4) \\
\end{array}$ \\
\hline \multirow{2}{*}{$\begin{array}{l}\text { Column, } \\
\text { Choi et al. [54] }\end{array}$} & $\begin{array}{c}\text { Physical } \\
\text { phenomenon }\end{array}$ & $\begin{array}{l}\text { Cracking and } \\
\text { spalling }\end{array}$ & $\begin{array}{l}\text { Moderate cracking } \\
\text { and spalling }\end{array}$ & $\begin{array}{c}\text { Degradation } \\
\text { without collapse }\end{array}$ & $\begin{array}{l}\text { Failure leading } \\
\text { to collapse }\end{array}$ \\
\hline & $\begin{array}{c}\text { Section, } \\
\text { ductility } \mu_{k}\end{array}$ & $\mu_{k}>1$ & $\mu_{k}>2$ & $\mu_{k}>4$ & $\mu_{k}>7$ \\
\hline
\end{tabular}

using the relative curvature ductility ratio of the pier, which is defined as

$$
\mu=\frac{\phi}{\phi_{\mathrm{cy} 1}}
$$

where $\varphi$ is the relative pier top curvature obtained from dynamic analysis and $\varphi_{\text {cyl }}$ is the relative pier curvature when the longitudinal reinforcement reaches its first yield. All EDPs for the highway bridge column are presented in Table 3.

In the structural response analyses, the curvature ductility of the pier or piles is recorded and the maximum response is employed as the damage index (DI) of the corresponding critical sections. The curvature ductility capacity, namely, $\mu_{\mathrm{C}}$ in equation (4), can be obtained based on expert judgments, experimental data, or numerical simulations. In this study, the value of $\mu_{\mathrm{C}}$ is determined by referencing the capacity-based limit state (LS) models defined in previous studies [55-57]. The curvature ductility of different sections is graduated into four damage LSs, namely, slight, moderate, extensive, and collapse. Table 3 summarizes the DI values corresponding to the four LSs of each section. In this paper, the index values provided by Choi et al. [54] in the table are used for seismic vulnerability analysis.

2.3. Input Ground Motions. In this study, the far-field suite of 22 records introduced in the FEMA P695 (2009) is considered to investigate the seismic fragility of the FSSI system, which occurred between 1971 and 1999. Among them, 8 events were from California earthquakes and 6 events were from five different foreign countries. For the farfield record set, event magnitudes range from M6.5 to M7.6 with an average magnitude of M7.0. Figure 6 represents the average spectrum of the far-field record set from FEMA and different acceleration response spectra with 5\% damping ratio.

2.4. Seismic Fragility of the Pier-Group Pile System. Figure 7 shows the computed demand values of different sections, i.e., Sec C and Sec D, with respect to the ground motion IM (PGA) in the logarithm coordinates. The linear regression results are also illustrated. It can be observed that the relationships between the various structural demands and the PGA value fit well with the corresponding log-linear models. Using the parameters obtained from the regression analyses in equations (2) and (3), the median and dispersion values for the seismic fragilities of various bridge components are calculated.

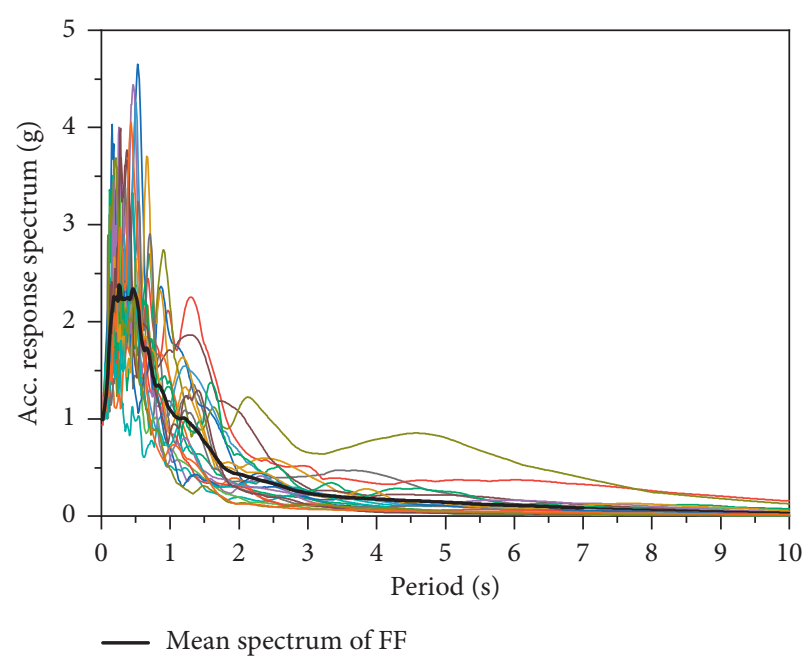

FIgURE 6: Acceleration response spectrum $(\mathrm{PGA}=1.0 \mathrm{~g})$ of the FF record subset from the FEMA.

Table 4 summarizes the corresponding fragility median and dispersion values of different critical sections of the pier and piles. The generated component fragility curves under the four damage LSs are plotted in Figure 8. As shown in Figure $8, \mathrm{Sec}$ C is the most vulnerable section in the example FSSI system for all of the four damage LSs, followed by Sec B and Sec A. The fragilities of Sec E are the lowest. This is owing to the fact that the bottom section of the pier suffers very large moment during earthquake excitations.

The seismic responses of Sec E are much lower since the stiffness and damping provided by surrounding soil are very limited. It can be observed from Figures 8(c) and 8(d) that the seismic fragilities of the critical sections other than Sec C are very low under the extensive and collapse damage, and the corresponding fragility median values are very high (as listed in Table 4), which means that the damage probabilities of these sections are negligible and the seismic performance of the FSSI system under higher damage LSs is controlled by Sec C.

\section{Parameter Analysis}

3.1. Effect of Pile-Water Interaction. To analyze the effect of pile-water interaction on different pier systems, there are two models including Model A and Model B are discussed in this section. Model A considers the pile-soil interaction, and the detail model is introduced in Section 2. Model B is assuming the soil rigid. In Model B, the piles are fixed on the interface section between soil layer and water. 


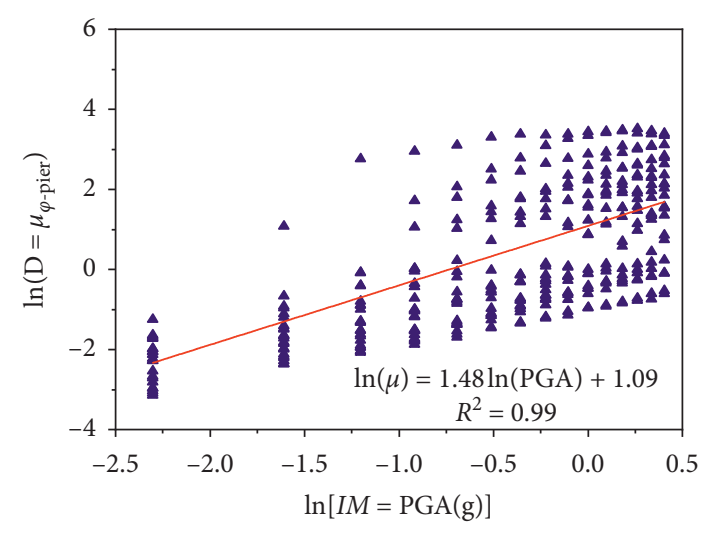

- Simulation data Linear regression

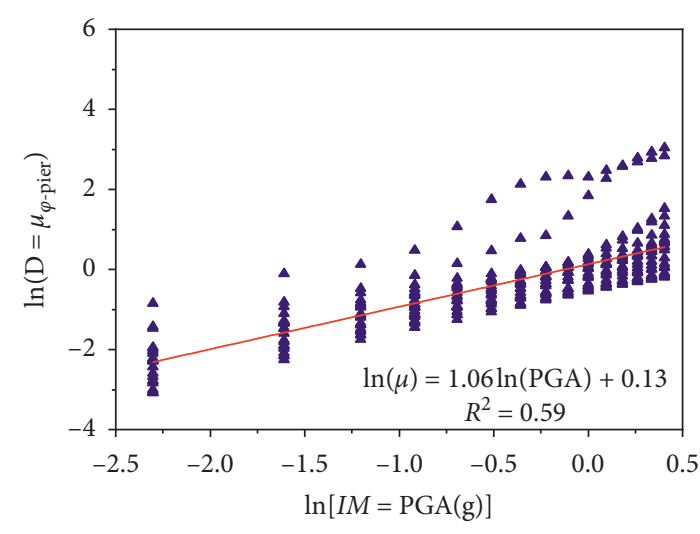

- Simulation data - Linear regression

(a)

(b)

FIgURE 7: Regression analyses of the demand values of different sections with respect to PGA. (a) Sec C and (b) Sec D.

Table 5 shows the fundamental period $\left(T_{1}\right)$ for Model A and Model B, which is $3.51 \mathrm{~s}$ and $2.25 \mathrm{~s}$. It indicates that assuming the fixed boundary condition will obviously decrease the fundamental period by $36 \%$. For the different model, the fundamental periods of foundation when considering FSI and without FSI are shown in Table 5. It can be seen that pile-water interaction can increase the fundamental period of the bridge pile foundation and it has more influence for Model A. When water depth is $40 \mathrm{~m}$, the fundamental period is increased about $4 \%$ for Model A while it is increased about $1 \%$ for Model B.

The effects of pile-water interaction on the seismic responses of the bridge pier are firstly investigated, where four earthquake records shown in Table 6 are used. Table 7 shows the maximum displacement on the pier head versus water depth. Table 8 shows the maximum curvature at Sec C versus water depth. It can be seen that the seismic responses of the bridge pier in the case of Model B are increased by the pilewater interaction and this influence increases as water depth increasing. However, for Model A, the seismic responses of the bridge pier may be increased or decreased by the pilewater interaction, which is relevant to the characteristics of the earthquake records, water depth, and dynamic properties of the bridge pier significantly changed by pile-soil interaction and pile-water interaction, as shown in Table 5. It should be noted that pile-water interaction can increase the seismic responses of the bridge pier in most cases. When water depth is $40 \mathrm{~m}$, the seismic responses of the bridge pier can increase about $10 \%$ in some cases.

Figures 9 and 10 show the fragility curves of Model A and Model B at Sec C for different water depth. It can be seen that pile-water interaction has slight influence on the fragility curves of the bridge pier in the present study and this influence is less than 5\%. Tables 9 and 10 show the probability ratio of fragility curves between considering FSI and without FSI. It can be seen that the value of fragility curves in the case of Model B is increased by the pile-water interaction and the probability ratio increases as water depth increases. However, pile-water interaction makes the value of fragility
TABLE 4: Median and dispersion values of FSSI component fragilities under four damage LSs.

\begin{tabular}{cccccc}
\hline \multicolumn{2}{c}{ Section } & Sec B & Sec C & Sec D & Sec E \\
\hline \multirow{4}{*}{$\mu_{\mathrm{IM}}(\mathrm{g})$} & Slight & 0.73 & 0.54 & 0.88 & 2.78 \\
& Moderate & 1.40 & 0.85 & 1.70 & 5.83 \\
& Extensive & 2.70 & 1.32 & 3.27 & 12.23 \\
& Collapse & 4.57 & 1.90 & 5.54 & 22.23 \\
\hline$\sigma_{\mathrm{IM}}$ & - & 0.75 & 0.84 & 0.63 & 0.46 \\
\hline
\end{tabular}

curves in the case of Model A decrease about 2\% when water depth is $40 \mathrm{~m}$. It also can be seen that the effects of pile-water interaction on fragility curves decrease as earthquake intensity increases. It should be noted that the numerical results conducted by Wang et al. [17] indicated that the FSI has significant effect on the seismic responses of the cylinder when the water depth is much larger than half height of the cylinder, while the effect of FSI on the seismic responses of the cylinder can be neglected when the water depth is less than half height of the cylinder. This study also indicates that the effect of FSI on the fragility curves can be neglected when the water depth is less than half height of the bridge pier.

3.2. Effect of Different Types of Ground Motions. The previous analysis only discussed the seismic vulnerability of the bridge pile foundation system subjected to far-field (FF) earthquakes. In fact, cross-sea piers may also suffer from near-field earthquakes as the widespread existence of submarine faults. Therefore, this section will discuss the seismic vulnerability of the bridge pile foundation system under different types of earthquakes. This paper still selects 28 recommended near-field (NF) records from the US specification FEMA P695 as input motions. All NF motions are recorded in the earthquakes occurred between 1976 and 2002. Among them, 7 records are from United States earthquakes (six in California) and another 7 records are from five different foreign countries. Event magnitudes range from M6.5 to M7.9 with an average magnitude of 


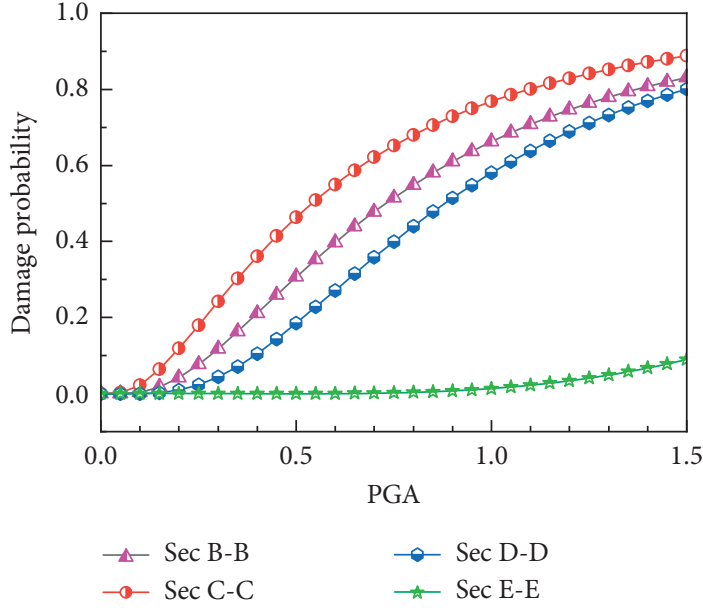

(a)

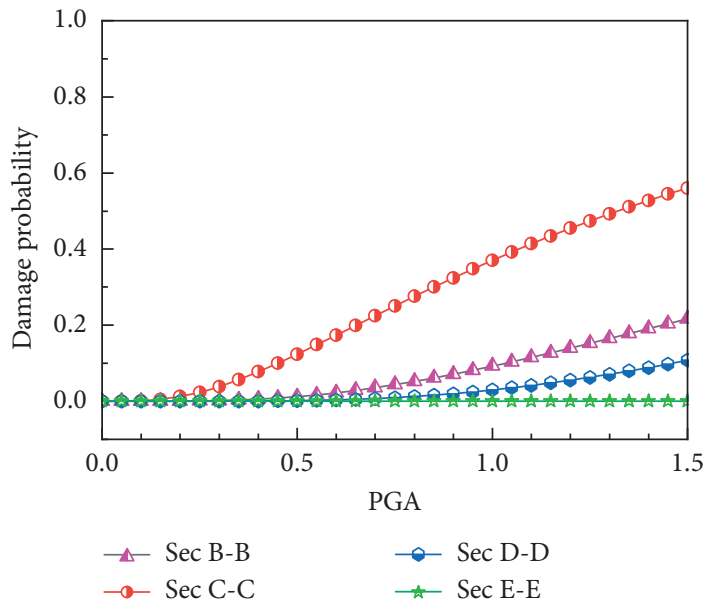

(c)

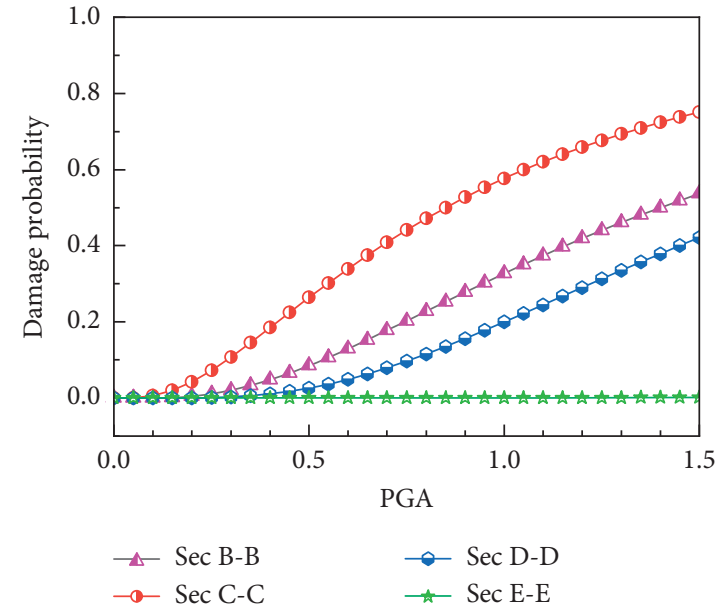

(b)

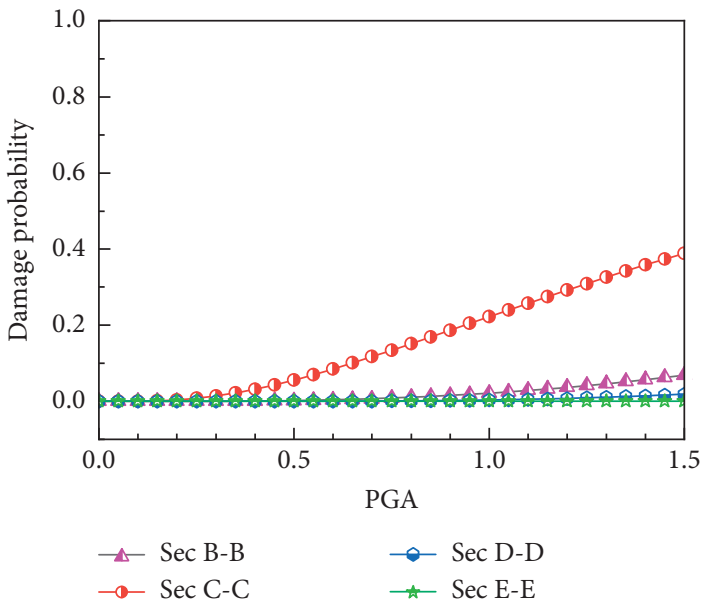

(d)

FIgURE 8: Seismic fragility curves of the critical sections. (a) Slight damage, (b) moderate damage, (c) extensive damage, and (d) collapse damage.

TABle 5: The fundamental period comparison between considering FSI and without FSI (unit: s).

\begin{tabular}{lccccccc}
\hline \multirow{2}{*}{ Model } & \multirow{2}{*}{ Without FSI } & & \multicolumn{3}{c}{ Considering FSI } \\
& & $10 \mathrm{~m}$ & $15 \mathrm{~m}$ & $20 \mathrm{~m}$ & $25 \mathrm{~m}$ & $30 \mathrm{~m}$ & $35 \mathrm{~m}$ \\
\hline Model A & 3.51 & 3.52 & 3.53 & 3.54 & 3.56 & 3.58 & 3.61 \\
Model B & 2.25 & 2.25 & 2.25 & 2.25 & 2.25 & 2.26 & 2.27 \\
\hline
\end{tabular}

TABLE 6: Summary of earthquake event for the far-field record set [58].

\begin{tabular}{lcccccc}
\hline \multirow{2}{*}{ ID no. } & \multicolumn{2}{c}{ Earthquake } & \multicolumn{2}{c}{ Recording station } \\
& Magnitude & PGA $(\mathrm{g})$ & Year & Event & Station name & Owner \\
\hline FF1 & 6.6 & 0.21 & 1971 & San Fernando & LA-Hollywood Stor & CDMG \\
FF2 & 6.5 & 0.35 & 1976 & Friuli, Italy & Tolmezzo & Delta \\
FF3 & 6.5 & 0.35 & 1979 & Imperial Valley & UNAMUCSD \\
FF4 & 6.5 & 0.38 & 1979 & Imperial Valley & El Centro Array \#11 & USGS \\
\hline
\end{tabular}


TABLE 7: The displacement of pier top node comparisons (unit: m).

\begin{tabular}{|c|c|c|c|c|c|}
\hline \multirow{2}{*}{ Model } & \multirow{2}{*}{ Excitations } & \multirow{2}{*}{ Without FSI } & \multicolumn{3}{|c|}{ Considering FSI } \\
\hline & & & $d=10 \mathrm{~m}$ & $d=20 \mathrm{~m}$ & $d=40 \mathrm{~m}$ \\
\hline \multirow{4}{*}{ Model A } & FF1 & 2.86 & 2.85 & 2.82 & 2.82 \\
\hline & FF2 & 0.43 & 0.43 & 0.43 & 0.43 \\
\hline & FF3 & 2.10 & 2.11 & 2.13 & 2.22 \\
\hline & FF4 & 1.88 & 1.93 & 1.98 & 2.10 \\
\hline \multirow{4}{*}{ Model B } & FF1 & 2.02 & 2.02 & 2.02 & 2.17 \\
\hline & $\mathrm{FF} 2$ & 0.54 & 0.54 & 0.54 & 0.55 \\
\hline & FF3 & 1.88 & 1.88 & 1.92 & 2.02 \\
\hline & FF4 & 1.66 & 1.66 & 1.67 & 1.74 \\
\hline
\end{tabular}

TABLE 8: The curvature of Sec C comparisons.

\begin{tabular}{|c|c|c|c|c|c|}
\hline \multirow{2}{*}{ Model } & \multirow{2}{*}{ Excitations } & \multirow{2}{*}{ Without FSI } & \multicolumn{3}{|c|}{ Considering FSI } \\
\hline & & & $d=10 \mathrm{~m}$ & $d=20 \mathrm{~m}$ & $d=40 \mathrm{~m}$ \\
\hline \multirow{4}{*}{ Model A } & FF1 & 0.015 & 0.015 & 0.015 & 0.014 \\
\hline & FF2 & 0.001 & 0.001 & 0.001 & 0.001 \\
\hline & FF3 & 0.010 & 0.010 & 0.010 & 0.010 \\
\hline & FF4 & 0.006 & 0.006 & 0.007 & 0.007 \\
\hline \multirow{4}{*}{ Model B } & FF1 & 0.011 & 0.011 & 0.011 & 0.012 \\
\hline & FF2 & 0.003 & 0.003 & 0.003 & 0.003 \\
\hline & FF3 & 0.010 & 0.010 & 0.010 & 0.011 \\
\hline & FF4 & 0.010 & 0.010 & 0.010 & 0.011 \\
\hline
\end{tabular}

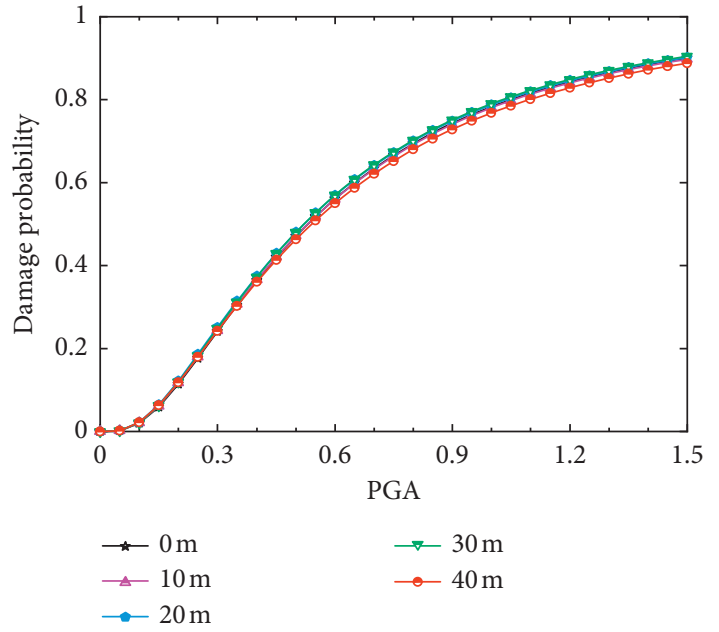

(a)

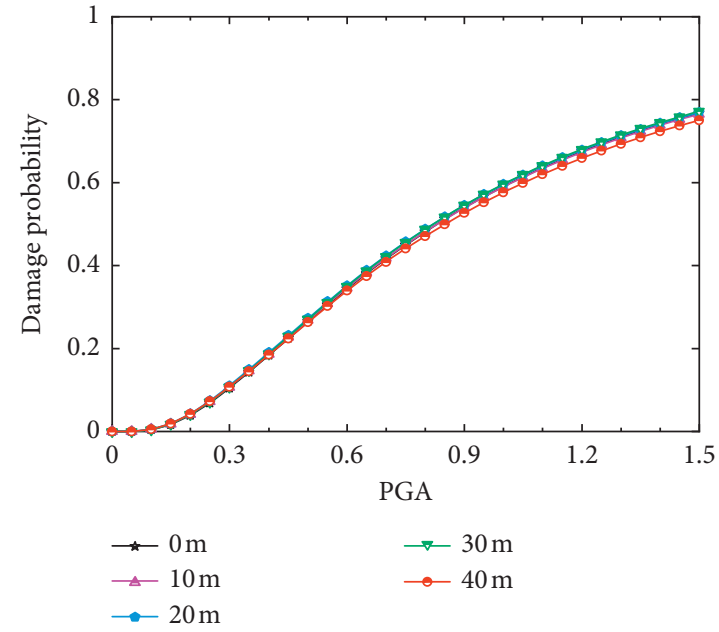

(b)

Figure 9: Continued. 


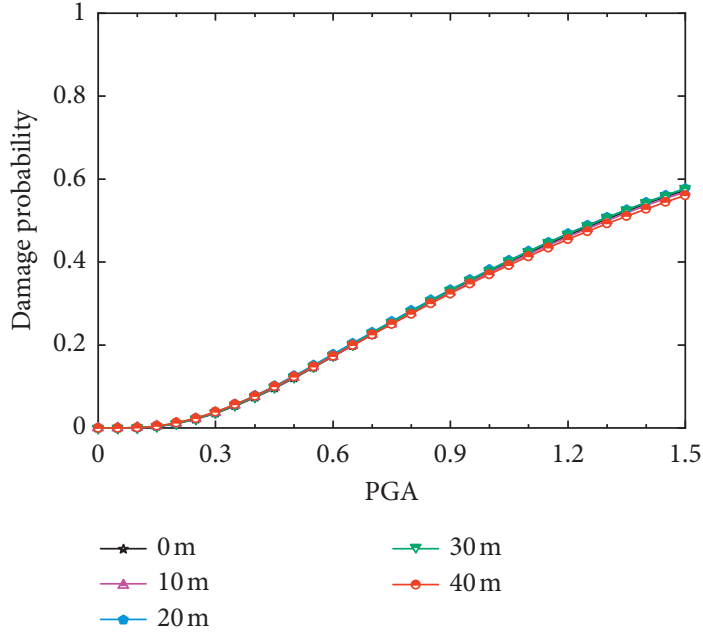

(c)

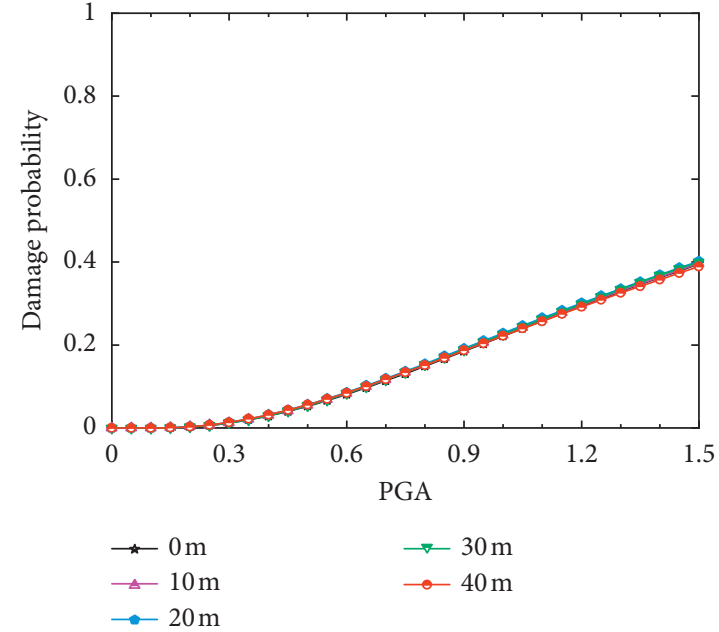

(d)

Figure 9: The seismic fragility curve of Sec C in Model A. (a) Slight, (b) moderate, (c) extensive, and (d) collapse.

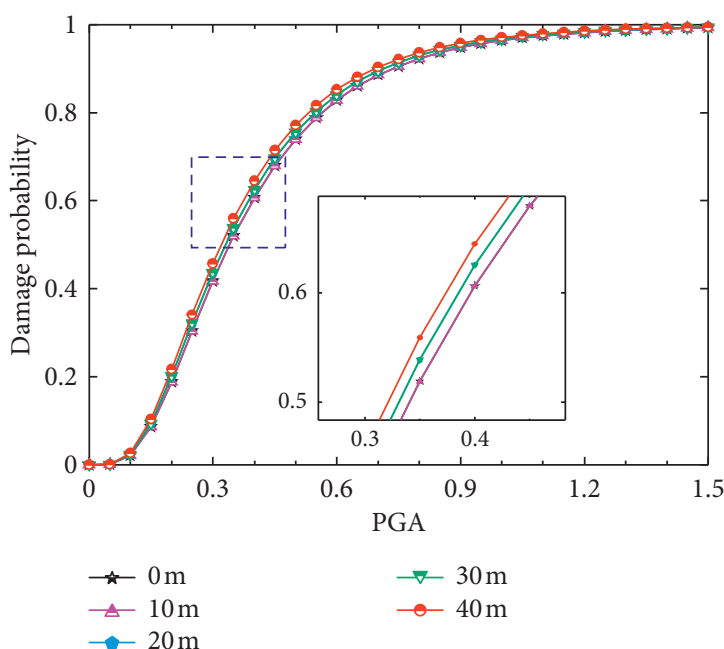

(a)

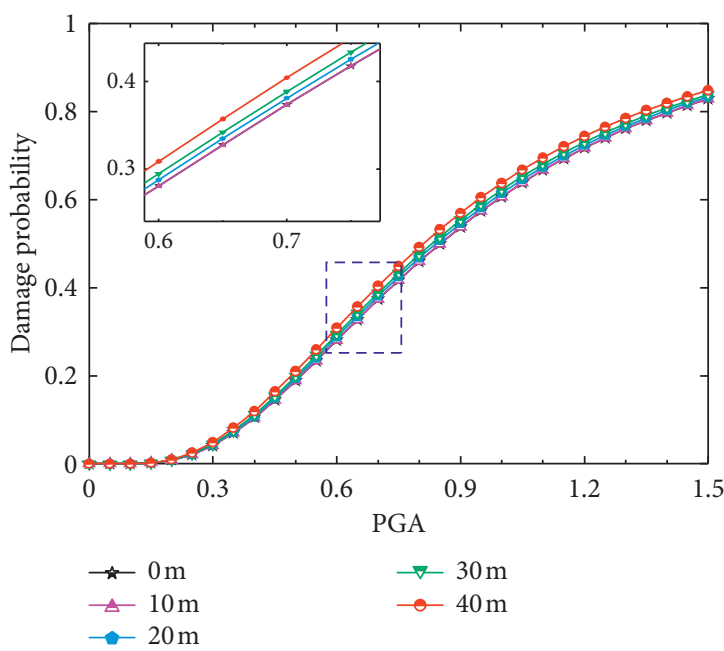

(c)

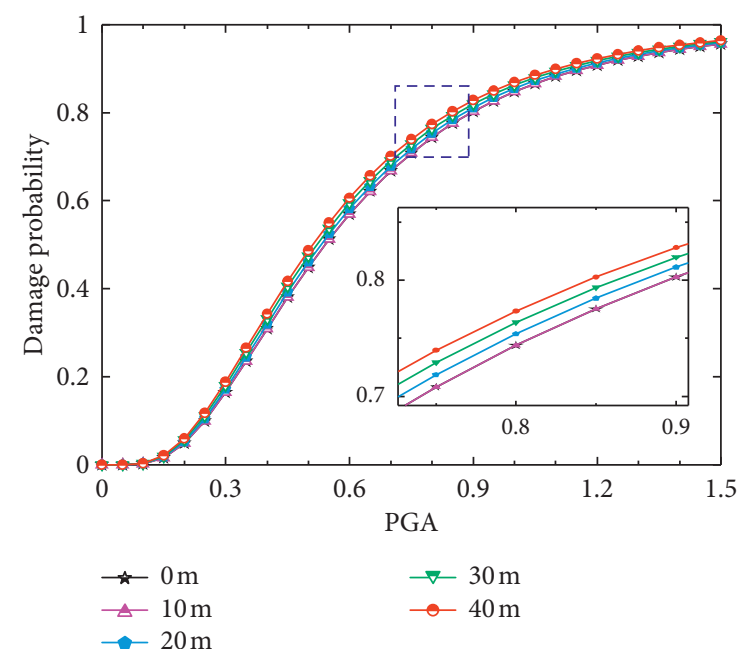

(b)

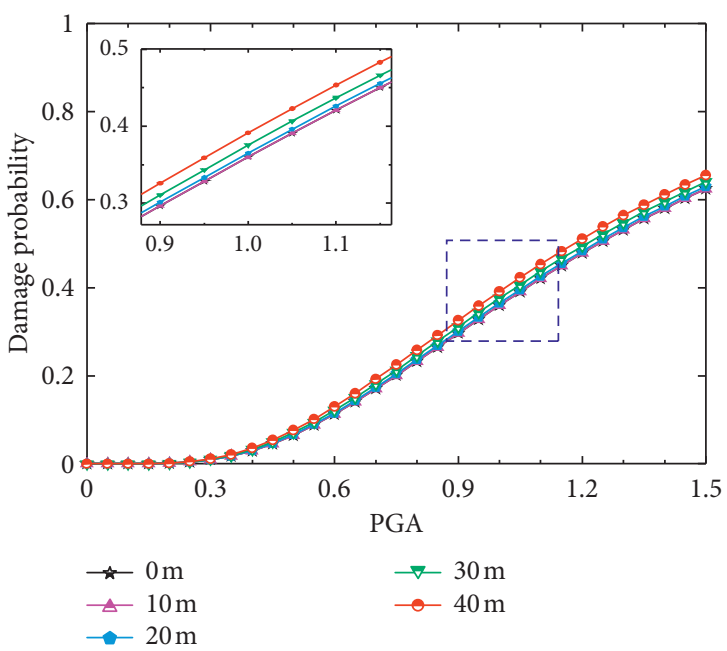

(d)

Figure 10: The seismic fragility curve of Sec C in Model B. (a) Slight, (b) moderate, (c) extensive, and (d) collapse. 
TABLE 9: The fragility of Sec C in slight LS comparisons.

\begin{tabular}{|c|c|c|c|c|c|}
\hline \multirow{2}{*}{ Model } & \multirow{2}{*}{ PGA } & \multirow{2}{*}{ Without FSI } & \multicolumn{3}{|c|}{ Considering FSI } \\
\hline & & & $d=10 \mathrm{~m}$ & $d=20 \mathrm{~m}$ & $d=40 \mathrm{~m}$ \\
\hline \multirow{3}{*}{ Model A } & 0.5 & 0.47 & 0.47 & 0.48 & 0.46 \\
\hline & 1.0 & 0.78 & 0.78 & 0.79 & 0.77 \\
\hline & 1.5 & 0.90 & 0.90 & 0.90 & 0.89 \\
\hline \multirow{3}{*}{ Model B } & 0.5 & 0.74 & 0.74 & 0.76 & 0.77 \\
\hline & 1.0 & 0.96 & 0.96 & 0.97 & 0.97 \\
\hline & 1.5 & 0.99 & 0.99 & 0.99 & 0.99 \\
\hline
\end{tabular}

TABLE 10: The fragility of Sec C in collapse LS comparisons.

\begin{tabular}{|c|c|c|c|c|c|}
\hline \multirow{2}{*}{ Model } & \multirow{2}{*}{ PGA (g) } & \multirow{2}{*}{ Without FSI } & \multicolumn{3}{|c|}{ Considering FSI } \\
\hline & & & $d=10 \mathrm{~m}$ & $d=20 \mathrm{~m}$ & $d=40 \mathrm{~m}$ \\
\hline \multirow{3}{*}{ Model A } & 0.5 & 0.05 & 0.05 & 0.06 & 0.06 \\
\hline & 1.0 & 0.22 & 0.22 & 0.23 & 0.22 \\
\hline & 1.5 & 0.40 & 0.40 & 0.40 & 0.39 \\
\hline \multirow{3}{*}{ Model B } & 0.5 & 0.07 & 0.07 & 0.07 & 0.08 \\
\hline & 1.0 & 0.36 & 0.36 & 0.37 & 0.39 \\
\hline & 1.5 & 0.62 & 0.62 & 0.63 & 0.66 \\
\hline
\end{tabular}

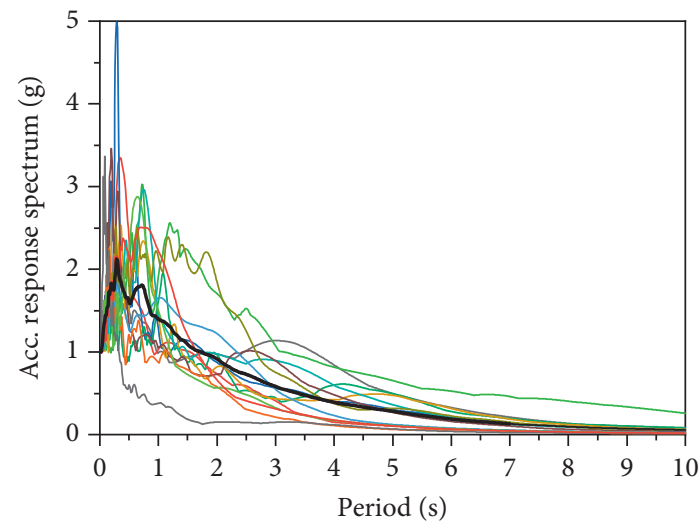

- Mean spectrum of PNF

(a)

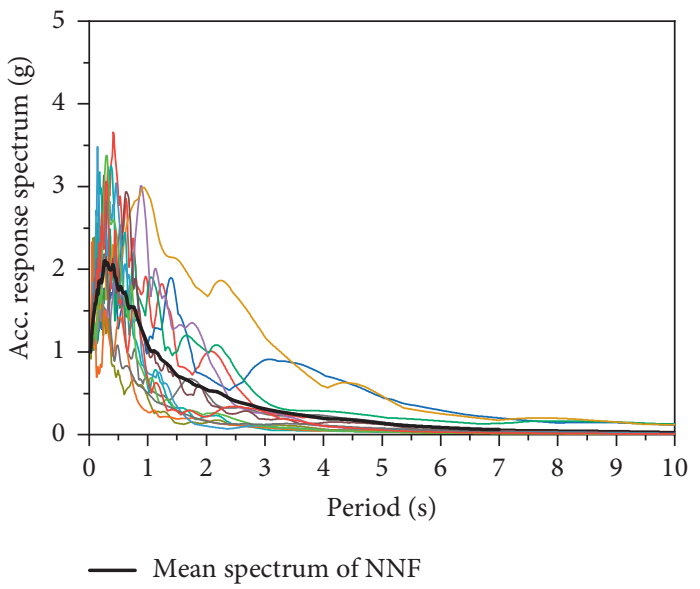

(b)

FIGURE 11: Acceleration response spectrum of NF ground motions (PGA=1.0 g). (a) Pulse near fault (PNF) and (b) no-pulse near fault (NNF).

M7.0. As judged by wavelet analysis classification of the records [59], recommended $\mathrm{NF}$ motions are divided into two sets of 14 NF motions: pulse near fault (PNF) and nopulse near fault. The acceleration response spectra of each motion of PNF set and NNF set $(P G A=1.0 \mathrm{~g})$ are shown in Figures 11(a) and 11(b). The mean acceleration response spectrum comparison is shown in Figure 12. For these three sets of motions, the FF has larger value in short-period range $(T<1 \mathrm{~s})$. However, PNF has larger value than FF and NNF when the period larger than $1 \mathrm{~s}$.

The fragility curves of Sec C and Sec D subject to NF ground motions in four LSs are shown in Figure 13. The damage probabilities of Sec C are always larger than Sec D when subjected to the NF ground motions, which is similar to the results of FF ground motions. It means that $\mathrm{Sec} C$ is always the most critical section for the FSSI system both for the FF and NF excitations. On the other hand, the fragility curves suffered to different type motions are compared. It is obvious that the damage probabilities suffer to PNF ground motions are significantly larger than NNF and FF for both Sec C and Sec D. And those of NNF and FF ground motions are closer. Taking excitation of $\mathrm{PGA}=1.0 \mathrm{~g}$ as an example, the damage probability comparisons are shown in Figure 14. For Sec $C$ at the slight damage LS, the damage probabilities under PNF are about $127 \%$ than the FF motions, while those under NNF are $87 \%$ than FF motions. This phenomenon can be explained from the acceleration response spectrum curve in Figure 14. For the fundamental period of the FSSI system $\left(T_{1}=3.6 \mathrm{~s}\right)$, the response of the PNF ground motion is significantly larger than NNF and FF. 


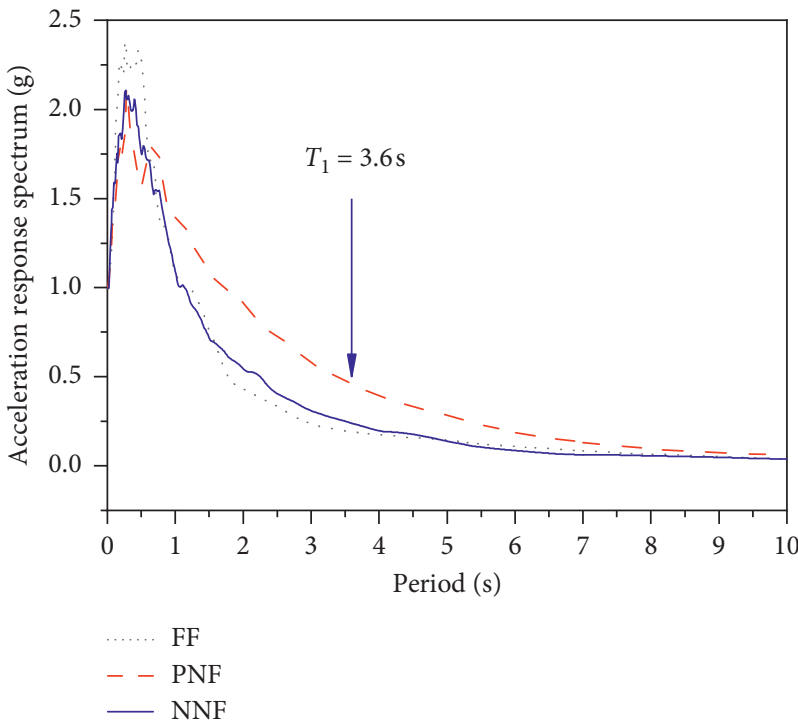

Figure 12: The mean acceleration response spectrum of NF ground motions $(\mathrm{PGA}=1.0 \mathrm{~g})$.

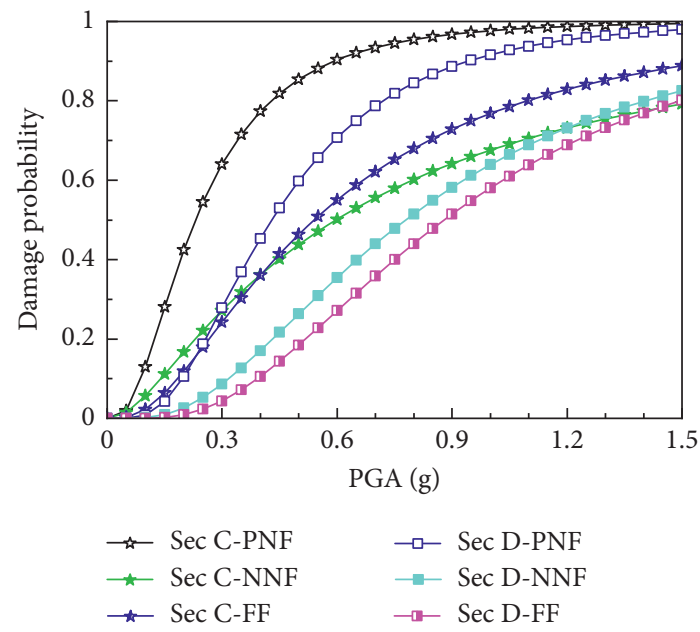

(a)

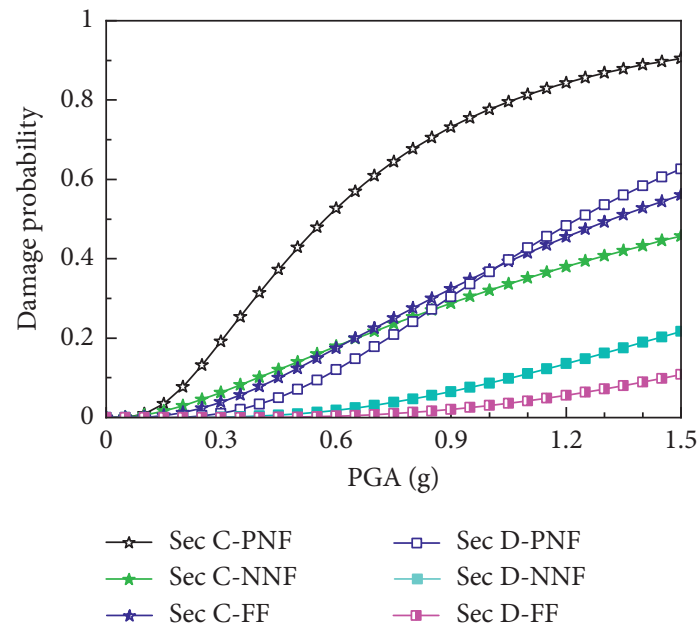

(c)

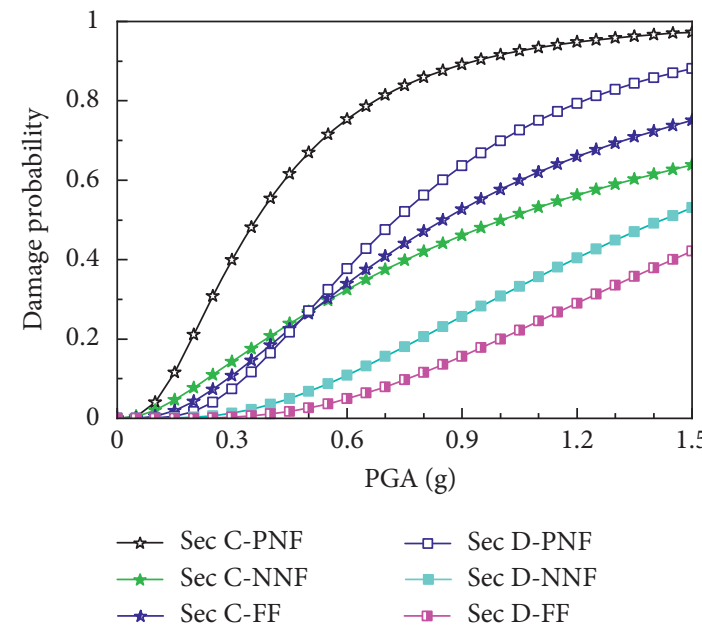

(b)

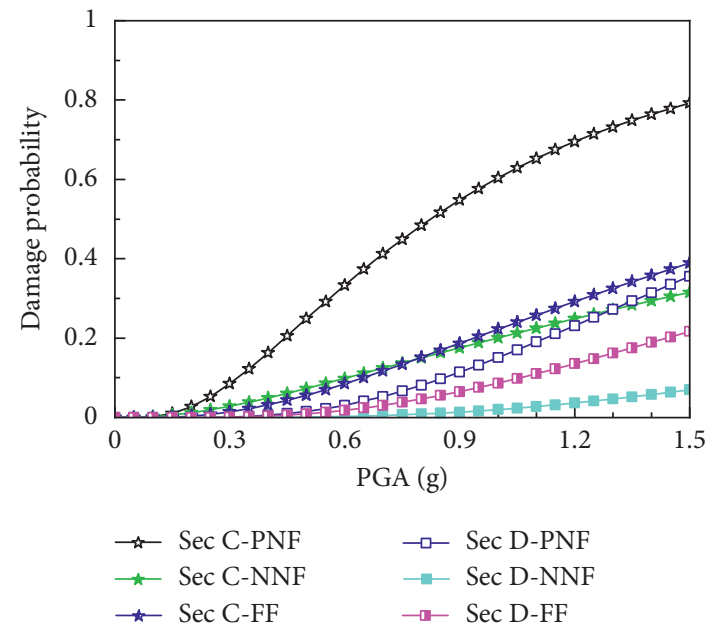

(d)

Figure 13: The seismic fragility curves subjected to different ground motions. (a) Slight level, (b) moderate level, (c) extensive level, and (d) collapse level. 


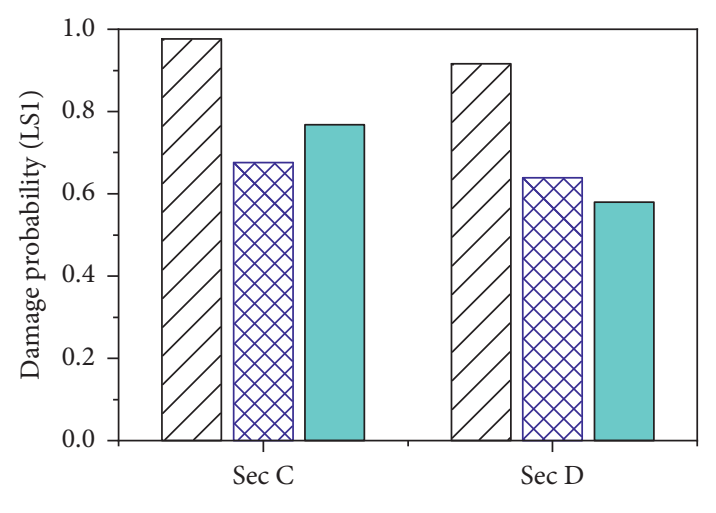

$\square Z$ PNF

NNF

$\square$ FF

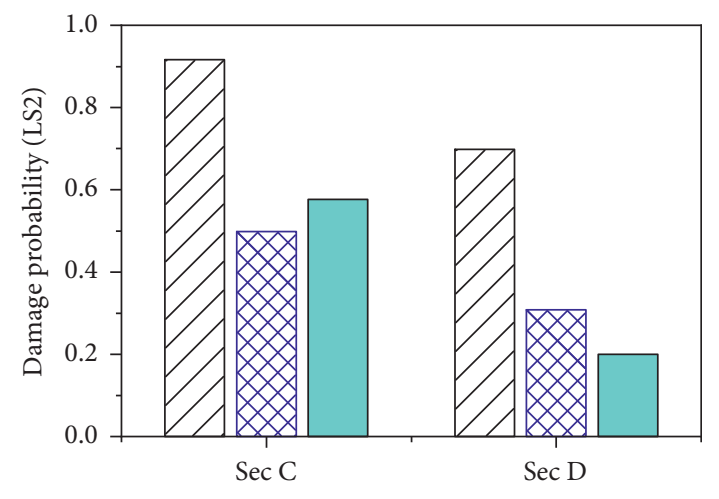

$\square \backslash \mathrm{PNF}$

NNF

$\square$ FF

(a)

(b)

FIgURE 14: The damage probability comparisons for PGA $=1.0$ g. (a) Slight level and (b) moderate level.

TABLE 11: The parameters of three different soil conditions.

\begin{tabular}{lccc}
\hline Soil type & $C_{\mathrm{u}}\left(\mathrm{kN} / \mathrm{m}^{2}\right)$ & $\mathcal{E}_{50}$ & $J$ \\
\hline Stiff & 100 & 0.005 & 0.25 \\
Moderate stiff & 80 & 0.01 & 0.375 \\
Soft & 40 & 0.02 & 0.5 \\
\hline
\end{tabular}
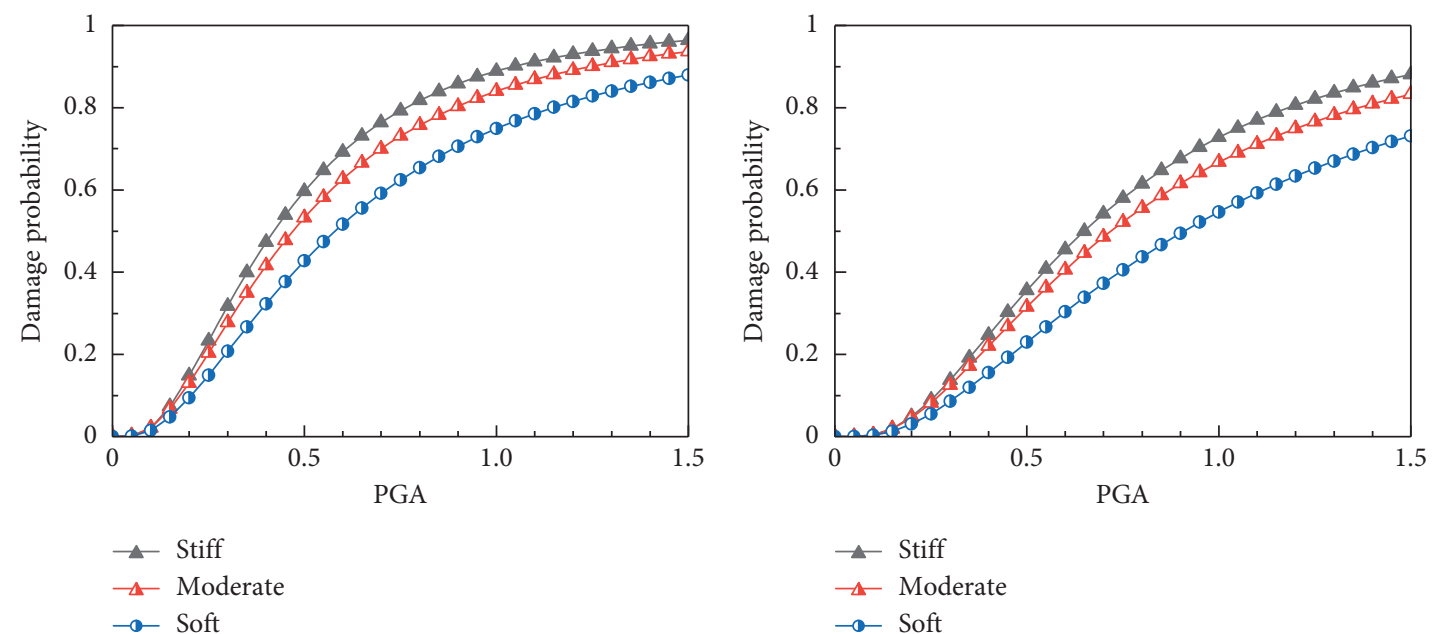

(a)

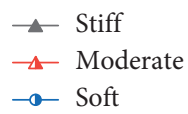

Figure 15: Continued.

(b) 


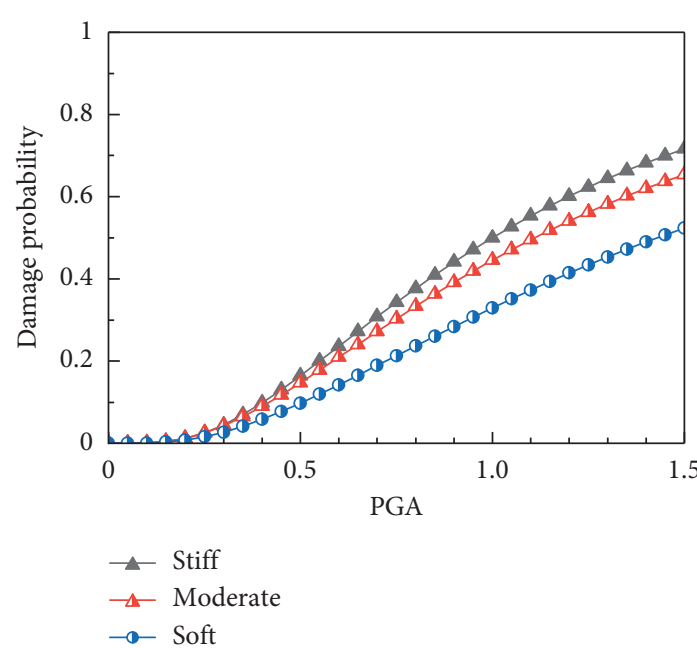

(c)

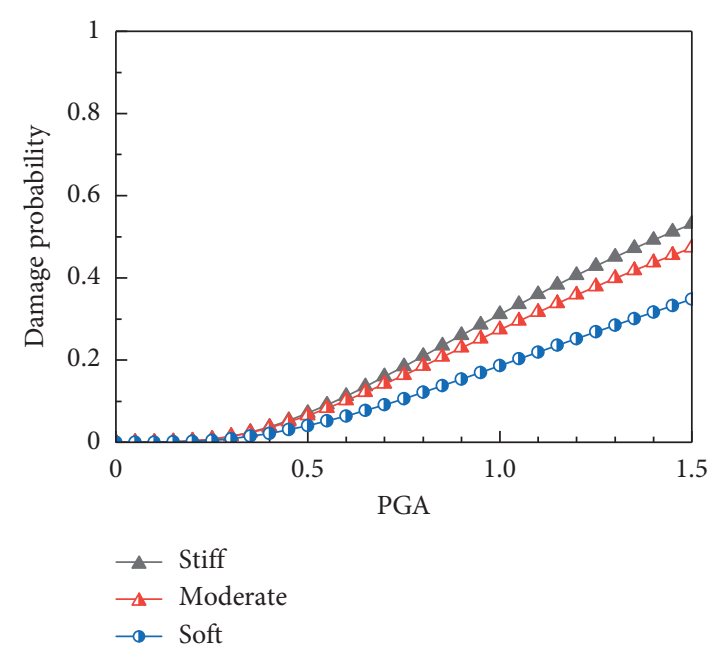

(d)

FIGURE 15: The seismic fragility curves of FSSI in different soil conditions. (a) Slight, (b) moderate, (c) extensive, and (d) collapse.

3.3. Effect of Different Soil Conditions. In order to examine the effects of plies at different soil conditions on the seismic fragilities of the bridge pile foundation system, the three different soil conditions including stiff, moderate stiff, and soft are discussed in this section. The value of the undrained shear strength $C_{u}$ is suggested by [60]. The values of $\varepsilon_{50}$ and $J$ are determined according to [47]. The parameters of three soil conditions are shown in Table 11.

The seismic fragility of the bridge pile foundation system under different soil conditions is calculated. The fragility curves of Sec C in four LSs are compared in Figure 15. We can observe that the fragilities in stiff soil are the highest in all LSs. It means that the FSSI in stiff soil is the most vulnerable to earthquake damage than other soil conditions. The fragilities in moderate soil are slightly less than stiff soil, while that in soft soil is obviously less than others. Taking the $\mathrm{PGA}=1.0 \mathrm{~g}$ as an example, the damage probabilities for stiff are 0.89 in the slight damage LS, which are 1.06 times and 1.19 times comparing to the moderate and soft soil site. For the other three damage LSs, the fragilities of bridge pile foundation at stiff soil are also slightly larger than moderate soil. And both are obviously larger than soft soil. The results seem can be explained from the changing of the system fundamental period. When the piles are surrounded by different soil types, the dynamic characteristics of the bridge piles systems are various, whose fundamental periods are $3.14 \mathrm{~s}, 3.39 \mathrm{~s}$, and $3.95 \mathrm{~s}$, respectively. It means the bridge pile system in the stiff site condition leads to fundamental period decrease of $8 \%$ for moderate soil and $21 \%$ for soft soil. In the result, the bridge pile foundation in stiff soil is most vulnerable to earthquake damage than other soil conditions.

\section{Conclusions}

A three-dimensional finite model is developed to reliably assess the seismic fragilities of the bridge pile foundation system considering FSSI, where effects of hydrodynamic added mass, soil conditions, and different types of ground motions on the fragilities are comprehensively taken into account. Based on the numerical examples, the obtained results can be drawn as follows:

(1) Pile-water interaction can increase the fundamental period of the bridge pile foundation, and it has more influence when pile-soil interaction is considered. In general, FSI can increase the seismic responses and fragilities of the bridge pier, and this influence increases as water depth increases and decreases as earthquake intensity increases. The effect of FSI on the fragility curves can be neglected when water depth is less than half height of the bridge pier.

(2) Compared to the FF ground motions, the PNF motions yield higher seismic responses and fragilities for the example bridge pile foundation (up to $27 \%$ ), and the NNF ground motions do not always lead to higher fragilities. In general, the influence of PNF motions should be seriously considered in seismic fragility analysis of the seacrossing bridge pile foundation considering fluidpile-soil interaction.

(3) The bridge pile foundation in stiff soil is most vulnerable to earthquake damage than other soil conditions. The damage probabilities for stiff case are 1.06 times and 1.19 times comparing to the moderate and soft soil site.

It should be noted that the influence of vertical excitations is not considered in this paper. As the notable influence on the long-span whole bridge, it will be carefully considered in the subsequent studies on the seismic response of the whole offshore bridge.

\section{Data Availability}

No data were used to support this study. 


\section{Disclosure}

The results and conclusions presented are of the authors and do not necessarily reflect the view of the sponsors.

\section{Conflicts of Interest}

The authors declare that there are no conflicts of interest regarding the publication of this paper.

\section{Acknowledgments}

This work was supported by the Postdoctoral Science Foundation of China (2018M631292), the Postdoctoral Science Foundation of Beijing (2018-ZZ-032), Natural Science Foundation of Fujian Province (2019J01233), and National Natural Science Foundation of China (51708010). The support is gratefully acknowledged.

\section{References}

[1] S. S. AbdelSalam, S. Sritharan, and M. T. Suleiman, "Current design and construction practices of bridge pile foundations with emphasis on implementation of LRFD," Journal of Bridge Engineering, vol. 15, no. 6, pp. 749-758, 2010.

[2] Y. Ding, R. Ma, Y.-D. Shi, and Z.-X. Li, "Underwater shaking table tests on bridge pier under combined earthquake and wave-current action," Marine Structures, vol. 58, pp. 301-320, 2018.

[3] C.-Y. Liaw and A. K. Chopra, "Dynamics of towers surrounded by water," Earthquake Engineering \& Structural Dynamics, vol. 3, no. 1, pp. 33-49, 1974.

[4] C. Liu, S. Zhang, and E. Hao, "Joint earthquake, wave and current action on the pile group cable-stayed bridge tower foundation: an experimental study," Applied Ocean Research, vol. 63, pp. 157-169, 2017.

[5] K. Wei, W. Yuan, and N. Bouaanani, "Experimental and numerical assessment of the three-dimensional modal dynamic response of bridge pile foundations submerged in water," Journal of Bridge Engineering, vol. 18, no. 10, pp. 1032-1041, 2013.

[6] Q. Han, J. Wen, X. Du, Z. Zhong, and H. Hao, "Nonlinear seismic response of a base isolated single pylon cable-stayed bridge," Engineering Structures, vol. 175, pp. 806-821, 2018.

[7] Q. Han, J. Wen, X. Du, and C. Huang, "Seismic response of single pylon cable-stayed bridge under scour effect," Journal of Bridge Engineering, vol. 24, no. 6, p. 05019007, 2019.

[8] C. C. Spyrakos, "Seismic behavior of bridge piers including soil-structure interaction," Computers \& Structures, vol. 43, no. 2, pp. 373-384, 1992.

[9] C. C. Spyrakos and C. Xu, "Soil-structure-water interaction of intake-outlet towers allowed to uplift," Soil Dynamics and Earthquake Engineering, vol. 16, no. 2, pp. 151-159, 1997.

[10] N. P. Tongaonkar and R. S. Jangid, "Seismic response of isolated bridges with soil-structure interaction," Soil Dynamics and Earthquake Engineering, vol. 23, no. 4, pp. 287302, 2003.

[11] J. Avilés and X. Li, "Hydrodynamic pressures on axisymmetric offshore structures considering seabed flexibility," Computers \& Structures, vol. 79, no. 29-30, pp. 2595-2606, 2001.

[12] B.-F. Chen, "3D nonlinear hydrodynamic analysis of vertical cylinder during earthquakes. I: rigid motion," Journal of Engineering Mechanics, vol. 123, no. 5, pp. 458-465, 1997.
[13] X. Du, P. Wang, and M. Zhao, "Simplified formula of hydrodynamic pressure on circular bridge piers in the time domain," Ocean Engineering, vol. 85, pp. 44-53, 2014.

[14] C. Y. Liaw and A. K. Chopra, "Earthquake analysis of axisymmetric towers partially submerged in water," Earthquake Engineering \& Structural Dynamics, vol. 3, no. 3, pp. 233-248, 1975.

[15] Y. Tanaka and R. T. Hudspeth, "Restoring forces on vertical circular cylinders forced by earthquakes," Earthquake Engineering \& Structural Dynamics, vol. 16, no. 1, pp. 99-119, 1988.

[16] A. N. Williams, "Earthquake response of submerged circular cylinder," Ocean Engineering, vol. 13, no. 6, pp. 569-585, 1986.

[17] P. Wang, M. Zhao, H. Li, and X. Du, "An accurate and efficient time-domain model for simulating water-cylinder dynamic interaction during earthquakes," Engineering Structures, vol. 166, pp. 263-273, 2018.

[18] Q. Li and W. L. Yang, "An improved method of hydrodynamic pressure calculation for circular hollow piers in deep water under earthquake," Ocean Engineering, vol. 72, pp. 241-256, 2013.

[19] H. Jiang, B. Wang, X. Bai, C. Zeng, and H. Zhang, "Simplified expression of hydrodynamic pressure on deep water cylindrical bridge piers during earthquakes," Journal of Bridge Engineering, vol. 22, no. 6, Article ID 04017014, 2017.

[20] A. Goyal and A. K. Chopra, "Simplified evaluation of added hydrodynamic mass for intake towers," Journal of Engineering Mechanics, vol. 115, no. 7, pp. 1393-1412, 1989.

[21] P. Wang, M. Zhao, and X. Du, "Analytical solution and simplified formula for earthquake induced hydrodynamic pressure on elliptical hollow cylinders in water," Ocean Engineering, vol. 148, pp. 149-160, 2018.

[22] P. Wang, M. Zhao, and X. Du, "Simplified formula for earthquake-induced hydrodynamic pressure on round-ended and rectangular cylinders surrounded by water," Journal of Engineering Mechanics, vol. 145, no. 2, p. 04018137, 2019.

[23] P. Wang, M. Zhao, X. Du, J. Liu, and J. Chen, "Simplified evaluation of earthquake-induced hydrodynamic pressure on circular tapered cylinders surrounded by water," Ocean Engineering, vol. 164, pp. 105-113, 2018.

[24] R. P. S. Han and H. Xu, "A simple and accurate added mass model for hydrodynamic fluid-structure interaction analysis," Journal of the Franklin Institute, vol. 333, no. 6, pp. 929-945, 1996.

[25] W. Yang and Q. Li, "A new added mass method for fluidstructure interaction analysis of deep-water bridge," KSCE Journal of Civil Engineering, vol. 17, no. 6, pp. 1413-1424, 2013.

[26] P. Wang, M. Zhao, and X. Du, “A simple added mass model for simulating elliptical cylinder vibrating in water under earthquake action," Ocean Engineering, vol. 179, pp. 351-360, 2019.

[27] W. G. Liao, "Hydrodynamic interaction of flexible structures," Journal of Waterway, Port, Coastal, and Ocean Engineering, vol. 111, no. 4, pp. 719-731, 1985.

[28] A. N. Williams, "Hydrodynamic interactions between submerged cylinders," Journal of Waterway, Port, Coastal, and Ocean Engineering, vol. 113, no. 4, pp. 364-380, 1987.

[29] P. Wang, M. Zhao, X. Du, and X. Cheng, "A finite element solution of earthquake-induced hydrodynamic forces and wave forces on multiple circular cylinders," Ocean Engineering, vol. 189, p. 106336, 2019.

[30] S. Corciulo, O. Zanoli, and F. Pisanò, "Transient response of offshore wind turbines on monopiles in sand: role of cyclic 
hydro-mechanical soil behaviour," Computers and Geotechnics, vol. 83, pp. 221-238, 2017.

[31] R. A. Kjørlaug and A. M. Kaynia, "Vertical earthquake response of megawatt-sized wind turbine with soil-structure interaction effects," Earthquake Engng Struct Dyn.vol. 44, pp. 2341-2358, 2015.

[32] J. Liu, X. Bao, D. Wang, and P. Wang, "Seismic response analysis of the reef-seawater system under incident SV wave," Ocean Engineering, vol. 180, pp. 199-210, 2019.

[33] Y. Han, "Study of vibrating foundations considering soil-pilestructure interaction for practical applications," Earthquake Engineering and Engineering Vibration, vol. 7, no. 3, pp. 321-327, 2008.

[34] P. Wang, M. Zhao, X. Du, J. Liu, and C. Xu, "Wind, wave and earthquake responses of offshore wind turbine on monopile foundation in clay," Soil Dynamics and Earthquake Engineering, vol. 113, pp. 47-57, 2018.

[35] M. B. Zaaijer, "Foundation modelling to assess dynamic behaviour of offshore wind turbines," Applied Ocean Research, vol. 28, no. 1, pp. 45-57, 2006.

[36] M. Mallick and P. Raychowdhury, "Seismic analysis of highway skew bridges with nonlinear soil-pile interaction," Transportation Geotechnics, vol. 3, pp. 36-47, 2015.

[37] R. Mo, H. Kang, M. Li, and X. Zhao, "Seismic fragility analysis of monopile offshore wind turbines under different operational conditions," Energies, vol. 10, no. 7, p. 1037, 2017.

[38] D. H. Kim, S. G. Lee, and I. K. Lee, "Seismic fragility analysis of $5 \mathrm{MW}$ offshore wind turbine," Renewable Energy, vol. 65, pp. 250-256, 2014.

[39] H. Zuo, K. Bi, H. Hao, and C. Li, "Influence of earthquake ground motion modelling on the dynamic responses of offshore wind turbines," Soil Dynamics and Earthquake Engineering, vol. 121, pp. 151-167, 2019.

[40] A. Martínez, M. A. Hube, and K. M. Rollins, "Analytical fragility curves for non-skewed highway bridges in Chile," Engineering Structures, vol. 141, pp. 530-542, 2017.

[41] S. Mazzoni, F. McKenna, M. H. Scott, and GL. Fenves, The Open System for Earthquake Engineering Simulation (OpenSees) User Command-Language Manual, University of California, " Berkeley, CA, USA, 2006.

[42] Q. Han, Y. Zhou, X. Du, C. Huang, and G. C. Lee, "Experimental and numerical studies on seismic performance of hollow RC bridge columns," Earthquakes and Structures, vol. 7, no. 3, pp. 251-269, 2014.

[43] B. D. Scott, R. Park, and M. J. N. Priestly, "Stress-strain behavior of concrete confined by overlapping hoops at low and high strain rates," American Concrete Institute, vol. 79, no. 1, pp. 13-27, 1982.

[44] G. Chang and J. Mander, "Seismic energy based fatigue damage analysis of bridge columns: part I-evaluation of seismic capacity," Technical Report 94-0006, NCEER, Buffalo, NY, USA, 1994.

[45] R. W. Boulanger, C. J. Curras, B. L. Kutter, D. W. Wilson, and A. Abghari, "Seismic soil-pile-structure interaction experiments and analyses," Journal of Geotechnical and Geoenvironmental Engineering, vol. 125, no. 9, pp. 750-759, 1999.

[46] Boulanger, R. W. 2000. "The pysimple1, tzsimple1, and qzsimple1 material models." Documentation For the OpenSees Platform. http://opensees.berkeley.edu.

[47] H. Matlock, Correlations for Design of Laterally Loaded Piles in Soft Clay, Offshore Technology Conference, Dallas, TX, USA, 1970.

[48] American Petroleum Institute (API). 2011. "Petroleum and Natural Gas Industries-specific Requirements for Offshore structure." Part4 - Geotechnical and Foundation Design Considerations.

[49] K. Karimi-Moridani, P. Zarfam, and M. Ghafory-Ashtiany, "Seismic failure probability of a curved bridge based on analytical and neural network approaches," Shock and Vibration, pp. 97-114, 2017.

[50] C. Li, H.-N. Li, H. Hao, K. Bi, and B. Chen, "Seismic fragility analyses of sea-crossing cable-stayed bridges subjected to multi-support ground motions on offshore sites," Engineering Structures, vol. 165, pp. 441-456, 2018.

[51] X. Wang, B. Zhu, and S. Cui, "Research on collapse process of cable-stayed bridges under strong seismic excitations," Shock and Vibration, vol. 2017, pp. 1-18, 2017.

[52] Y. Xie, J. Zhang, R. DesRoches, and J. E. Padgett, "Seismic fragilities of single-column highway bridges with rocking column-footing," Earthquake Engineering \& Structural Dynamics, vol. 48, no. 7, pp. 843-864, 2019.

[53] C. A. Cornell, F. Jalayer, R. O. Hamburger, and D. A. Foutch, "Probabilistic basis for $2000 \mathrm{sac}$ federal emergency management agency steel moment frame guidelines," Journal of Structural Engineering, vol. 128, no. 4, pp. 526-533, 2002.

[54] E. Choi, R. DesRoches, and B. Nielson, "Seismic fragility of typical bridges in moderate seismic zones," Engineering Structures, vol. 26, no. 2, pp. 187-199, 2004.

[55] Y. Pang, X. Wu, and W. Yuan, "Seismic fragility analysis of cable-stayed bridges considering different sources of uncertainties," Journal of Bridge Engineering, vol. 19, no. 4, Article ID 04013015, 2013.

[56] J. Zhang and Y. Huo, "Evaluating effectiveness and optimum design of isolation devices for highway bridges using the fragility function method," Engineering Structures, vol. 31, no. 8, pp. 1648-1660, 2009.

[57] J. Zhong, J.-S. Jeon, W. Yuan, and R. DesRoches, "Impact of spatial variability parameters on seismic fragilities of a cablestayed bridge subjected to differential support motions," Journal of Bridge Engineering, vol. 22, no. 6, p. 04017013, 2017.

[58] Applied Technology Council, Quantification of Building Seismic Performance Factors, FEMA, Washington, DC, USA, 2009.

[59] J. W. Baker, "Quantitative classification of Near-Fault ground motions using wavelet analysis," Bulletin of the Seismological Society of America, vol. 97, no. 5, pp. 1486-1501, 2007.

[60] M. H. E. Naggar and K. J. Bentley, "Dynamic analysis for laterally loaded piles and dynamic p-y curves," Canadian Geotechnical Journal, vol. 37, no. 6, pp. 1166-1183, 2000. 